\title{
Strategies to reduce the risk of side wind induced accident on heavy truck
}

\author{
L. Salatia ${ }^{\mathrm{a}}$ P. Schito ${ }^{\mathrm{a}}$, F. Cheli ${ }^{\mathrm{a}}$ \\ ${ }^{a}$ Dipartimento di Meccanica - Politecnico di Milano, Milano (MI) Italy \\ luigi.salati@polimi.it_paolo.schito@polimi.it_federico.cheli@polimi.it
}

\begin{abstract}
Vehicles, in particular high-sided lorries and trucks, can be at risk of wind-induced accidents such as overturning and/or side slip, especially on exposed sites such as embankments, viaducts and bridges. A first solution, lies in designing fences and a lateral shield to be placed both at the edges of the bridge and close to the tower, thereby shielding the vehicle from cross-wind. Nevertheless, it is also possible to optimize the aerodynamic response of the vehicle. In this work, several strategies were used and compared to optimized the aerodynamic response of the Heavy Good Vehicle (HGV) in crosswind: changing of the shape of the trailer, vortex Generators (VGs) installed on the leading edge of the trailer and passive devices installed along the sides/top of the trailer. Front-rear trailer devices, previously designed and patented by the author, positioned on the sides of the trailer reduced the overturning moment by about $8 \%$. Steady state and time variant CFD simulations were used. The numerical models were validated with wind tunnel test.
\end{abstract}

\section{Introduction}

Vehicles, in particular high-sided lorries and trucks, can be at risk of wind-induced accidents such as overturning and/or side slip, especially on exposed sites such as embankments, viaducts and bridges. Since this represents a serious concern for the running safety of vehicles, it has been widely investigated in literature [1]-[6].

In this condition, the yaw angle (the angle between the vehicle speed and the wind direction) can be higher than $30^{\circ}$. Higher is the lateral wind, higher is the yaw angle experienced by the vehicle, and higher is the side force and the yawing moment as example [9]. At this crosswind, the aerodynamic of the vehicle is mostly effect from the box shape of the trailer. Higher is the yaw angle, higher is the quantity of the flow that directly hit the side of trailer generating high pressure on the vehicle. The flow, approaching the side of the vehicle is deviated over the surface of the side of the truck in the vertical direction: some of said flow moves down, and some moves up. On the top corner of the trailer, the flow separates generating high turbulence responsible of the previously mentioned change in the aerodynamic forces. In Figure 1-1, it is showed the pressure distribution over the heavy truck surface for a yaw angle, the angle between the wind direction and vehicle speed, of $30^{\circ}$ computed in previous author's work [10].

MacArthur et al. [11], showed that the stream-wise vortex separated off the roof of the trailer is separated from the bulk velocity wake and affects the crosswind stability.

This may lead the vehicle, in the worst case, to vehicle rollover or undesired lane changes and thus represents a critical concern for running safety.

The negative effects of later wind on the heavy truck handling are even worst when the vehicle is passing through the wake of towers of bridges largely exposed to crosswind. As the vehicle approaches the tower wake, a sudden change in the aerodynamic forces occurs due to the wind speedup at the sides of the pylon, and, in the most dangerous condition, a very skilled response is required from the driver to avoid undesired lane changes and/or rollover [12]. 
A first solution to reduce this problem lies in designing fences and a lateral shield to be placed both at the edges of the bridge and close to the tower, shielding the vehicle from cross-wind.

The design of these shields is however an extremely challenging task. They must be customized and tailed on the specific infrastructure for which they are designed, since it must account for dynamic coupling of aerodynamic loads (depending on the infrastructure layout) and vehicle-driver response.

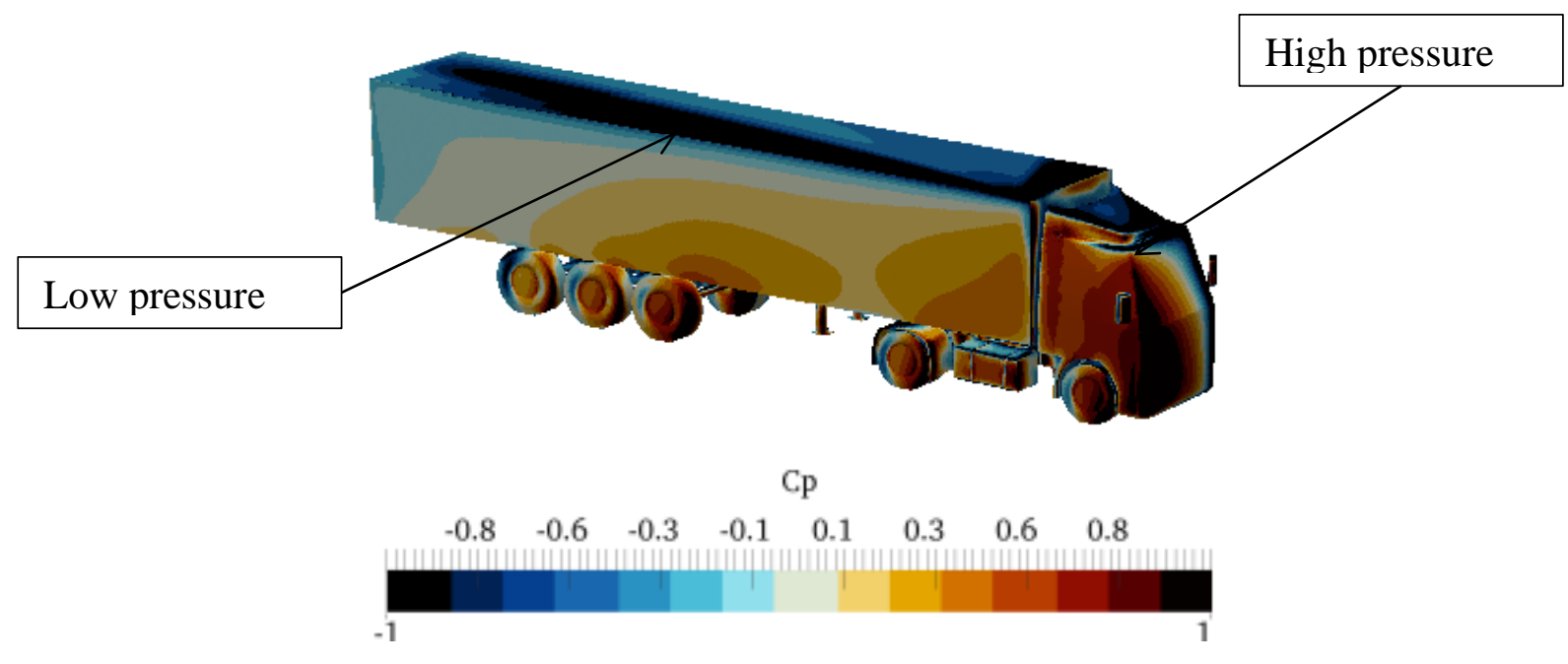

Figure 1-1. Pressure coefficient over the HGV surface for a yaw angle of $30^{\circ}$ computed in previous author's work [10].

An interesting work in designing lateral shield was done in Argentini at al.[13]. The Wind tunnel experiment were performed on a 1:40 scale model on the new three-tower, cable-stayed bridge between Fife and Edinburgh designed in the "Forth Replacement Crossing" (FRC) project. The FRC is a major infrastructure project for Scotland, designed to safeguard a vital connection in the country's transport network.

Several configurations have been tested, with zero velocity for both the vehicle and the pylon. The relative position between tower and truck were varied by positioning the vehicle in the nearest lane downwind the tower, and testing several different shieldings near the tower, in cross-wind conditions. Side force and yawing moment on the HGV have been halved.

An interesting work was carried out in the EC project WEATHER which involved, among others, Birmingham University, Nottingham University and Politecnico di Milano: an alarm system, aimed at warning the driver about rollover risk associated with high cross-wind, was developed in Cheli et al. [5], [6], [7]).

However, it is also possible to optimize the aerodynamic response of the vehicle.

The simplest way to reduce the side force acting on the HGV is to change the shape of the trailer from the standard rectangular one, making the corner between the top and the side of the trailer as smooth as possible.

In this way, the load capacity of the HGV is reduced. If the volume reduction is such that it does not preclude positioning inside the trailer of the pallet, this type of trailer shape changes could be easier to adopt from the transport community.

Rossitto et al. [14], show that aerodynamic lift forces for a fastback vehicle are largely affected by the rounding of the roof/backlight intersection.

Other possible solution could be the "adding" of external passive devices to the trailer to reduce the side force.

Several aerodynamic devices are currently used to reduce the drag force of the vehicle, among which the most common ones are:

$>$ cab roof fairings and side fairings (9-17\% drag reduction - Drollinger [15]; Cooper [16]; Leuschen and Cooper [17]); 
trailer-front fairing (7-10\% drag reduction - Garry [18]; Watkinset al.[19]);

$>$ tractor and trailer side-skirts (4-6\% drag reduction - Garry [20]; Ingram [21]);

$>$ boat-tails and base flaps (7.5\% drag reduction - McCallen et al. [22]; Cooper [16]).

In previous author work, the Front-rear trailer device were developed [9], [23]. These elliptic aerodynamic appendices, shown in Figure 2-18, are installed in the front and rear part of the trailer (see Figure 2-17 configuration " $\mathrm{D}+\mathrm{E}+\mathrm{F}+\mathrm{G}$ "). The device layout " $\mathrm{D}+\mathrm{E}+\mathrm{F}+\mathrm{G}$ " can reduce the overall vehicle drag around $10 \%$, with high beneficial in terms of fuel saving.

In Figure 1-2, it is reported a comparison between the target vehicle and one equipped with the Front trailer device. A first separation region occurred in the top-front of the trailer (indicated as "top-front vortex") moving along the top of the trailer with a consistent generation of drag. Subsequently, at the rear of the trailer, two main vortices were generated: one from the top-rear of the trailer and another one from the bottom-rear part.

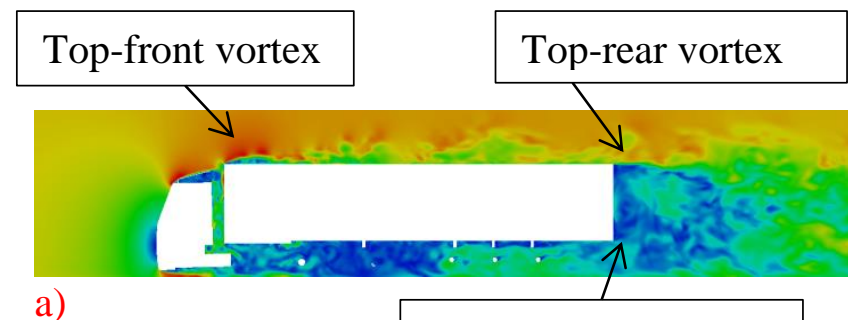

a)

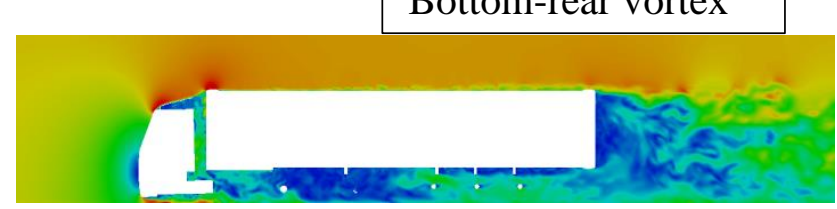

c)

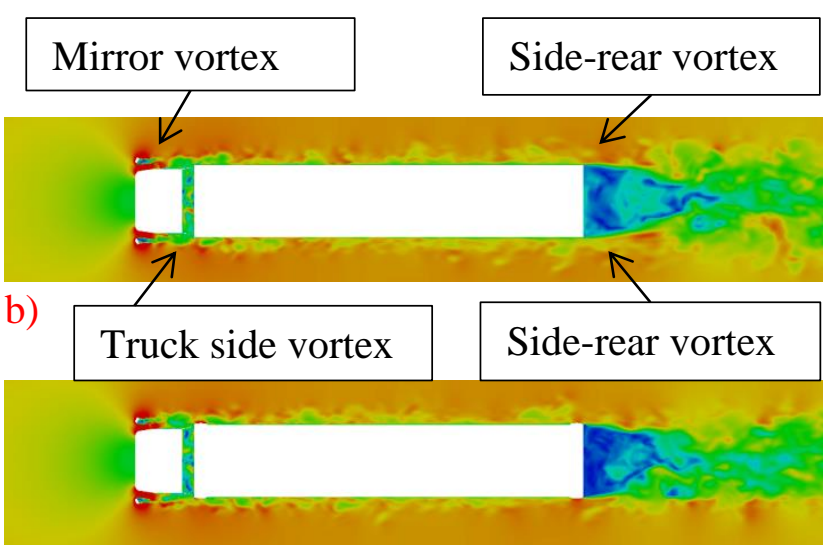

d)

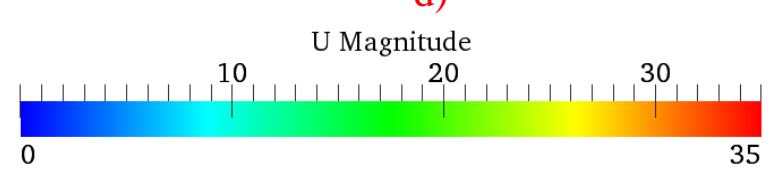

Figure 1-2. Instantaneous velocity contour plot at $\mathrm{y}=0 \mathrm{~m}$ : a) target vehicle, c) HGV equipped with Front-rear trailer device; Instantaneous velocity contour plot at $\mathrm{z}=2.6 \mathrm{~m}$ : b) target vehicle, d) HGV equipped with Front-rear trailer device.

Analyzing the top view of the vehicle (Figure 1-2-b, Figure 1-2-d), the first separation occurs on the side mirrors generating a high frequency vortex shedding; while a second separation, starts from the side of the truck. These two mixed, vortices move along the side surface of the trailer with a consistent generation of drag. At the end of the trailer, two main side-rear vortices are developed with almost the same size and frequency, but with opposite phases.

When the Front-rear trailer device were installed, the main separation region on the top front of the trailer do not occur: the presence of the devices organizes the flow that does not develop large vortex structures but tends to be more organized. The smaller turbulent content moving along the top/sides of the trailer decreases the overall drag of the vehicle.

Consequentially, also the flow approaching the rear device is more organized and the wake in the rear part of the trailer is smaller than the one of the target vehicles, decreasing the overall vehicle drag.

Reducing drag on a bluff body can be also obtained either by streamlining the shape of the HGV (as with the front trailer device) or by other mechanical strategies as moving skin, vanes, discharging high velocity fluid, suction, air jet injected in the flow field over the bluff body surface and vortex generators.

Vortex Generators (VGs) were developed on aircraft wings [24] to control the boundary layer and delay separation. When the boundary layer remains closer to the surface, the aircraft is more stable and the aerodynamic stall can be avoided. VGs are normally located ahead of the separation point 
position and can have several different shapes: rectangular, triangular, ogive, delta wing, etc. VGs are used successfully in other engineering sectors, such as wind turbine blades and engine inlet duct, to name a few [25]-[29]. The device introduces a vortical structure in the boundary layer (BL) mixing the high-momentum flow on the external layer of the BL with the low-momentum flow over the surface energizing the whole BL again. VGs can be used in matrix arrays mainly in co-rotating and counter-rotating VGs [30].

The first of these devices used to reduce the heavy truck drag was shown in [31] where Vortex Strake Devices (VSDs) were added at the top and rear sides of the trailer.

Several kinds of VGs and VG combinations can be successfully adopted to reduce HGV overall drag as show in [32].

In this work, the authors want to investigate different strategies to reduce the risk overturning of the heavy truck in a normal driving condition where an HGV is travelling in straight road with a constant lateral wind in space and time.

In this work, three main ways are adopted and compared to reduce the lateral force, yawing moment and the overturning risk:

Changing of the shape of the trailer.

$>$ Vortex Generators (VGs) installed on the leading edge of the trailer.

$>$ Front-rear trailer devices, previously developed from the authors ([9], [23]), installed along the sides/top of the trailer.

\section{Methodology}

\subsection{Target Vehicle}

A truck geometry corresponding to a common truck currently available on the EU streets was used. The heavy-truck model was simplified for CFD studies (see Figure 2-1): the cooling system and bracket that holds the mirrors were neglected, as well as the turning lights and the vehicle registration plate holder. The base model was already provided with cab roof fairings, side fairings, wheel houses for the tractor tires and a suitable design of the front corner radius of the tractor. All these devices are currently available on most European heavy trucks.

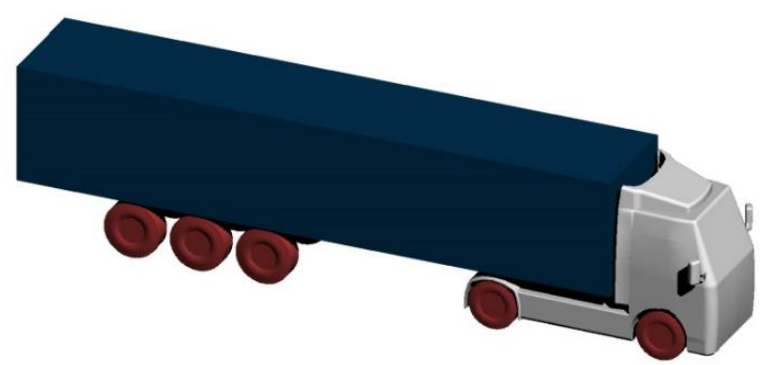

Figure 2-1. Heavy truck geometry: simplified geometry used as target vehicle.

The lower part of the wheels was duly modeled to reproduce the contact area between the tires and the ground and the deformation of the wheels. The overall dimensions of the target vehicle (without the mirrors) in scale 1:1 are reported in Table 2-1.

Table 2-1. Truck overall dimensions in scale 1:1.

\begin{tabular}{|c|c|c|}
\hline length & width & height \\
\hline$[\mathrm{m}]$ & {$[\mathrm{m}]$} & {$[\mathrm{m}]$} \\
\hline 15.6 & 2.5 & 4.0 \\
\hline
\end{tabular}




\subsection{Numerical model}

Computational meshes are generated using the meshing tool provided by the open-source CFD framework Open-FOAM ${ }^{\circledR}$ in full scale and then are scaled in 1:10. The generated mesh is a fully Cartesian grid in the entire domain, with layers on the truck surface.

Different simulations were performed to optimize the computational domain dimension related to the physics of the phenomena, especially in cross-wind. The computational domain (see Figure 2-2) is the optimum solution to avoid the blockage effect of the truck in the domain and to decrease the computational cost.

The reference system is placed on the ground along the truck centerline. Positive $X$ axis is directed according to the truck speed; positive $\mathrm{Z}$ axis is directed vertically and the $\mathrm{Y}$ axis has the truck transverse direction.

Drag, side and lift force were computed as the force applied on the vehicle in $\mathrm{x}, \mathrm{y}$ and $\mathrm{z}$ direction according to the reference system in Figure 2-2.

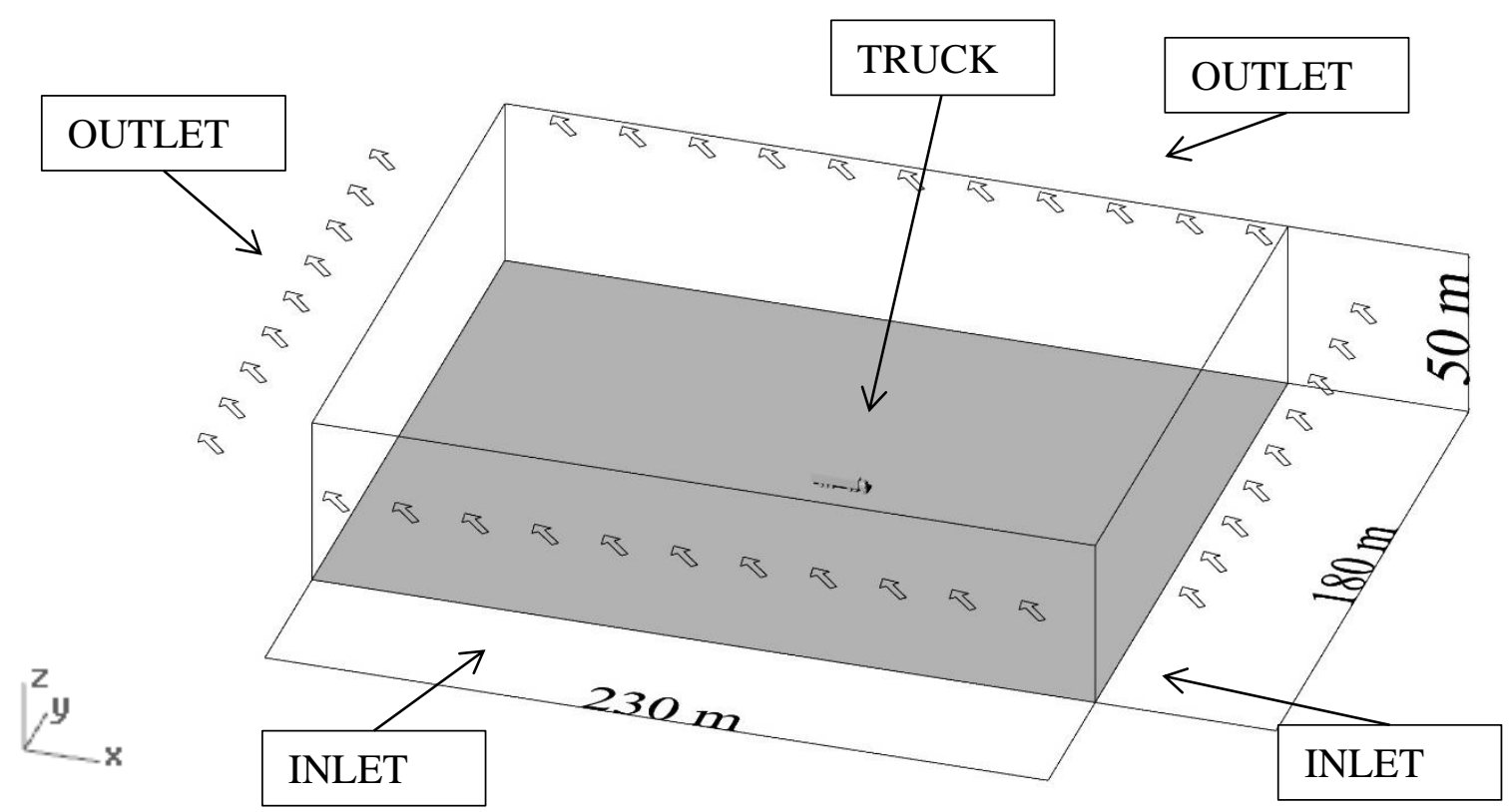

Figure 2-2. Computational domain and reference system in scale 1:1.

Truck trailer aerodynamic force coefficients were calculated according to the following:

$\mathrm{C}_{X}=-\frac{\mathrm{F}_{\mathrm{X}}}{0,5 * \rho * \mathrm{U}_{\infty}^{2} * \mathrm{~A}_{\text {front }}} \quad \mathrm{C}_{\mathrm{Y}}=\frac{\mathrm{F}_{\mathrm{Y}}}{0,5 * \rho * \mathrm{U}_{\infty}^{2} * \mathrm{~A}_{\text {lat }}} \quad \mathrm{C}_{\mathrm{Z}}=\frac{\mathrm{F}_{\mathrm{Z}}}{0,5 * \rho * \mathrm{U}_{\infty}^{2} * \mathrm{~A}_{\text {front }}}$

where $\rho$ is the air density, $U_{\infty}$ is defined as $U_{\infty}=\left(U_{\text {truck }}^{2}+U_{\text {wind }}^{2}\right)^{0,5}, A_{\text {front }}\left(8,99 m^{2}\right.$ in scale 1:1) is the frontal area of the vehicle, while $A_{\text {lat }}\left(52,73 \mathrm{~m}^{2}\right.$ in scale 1:1) is the lateral area, $\mathrm{L}$ is the length, $\mathrm{H}$ the height and $\mathrm{B}$ the width of the HGV.

Different grids from 39.7 million elements to 80.4 million elements were tested to check the grid independency on the target vehicle (see Table 2-2). The overall drag and side force of the vehicle were used as parameters to monitor the grid independency. The chosen grid agrees with the SAE Standard J2966 [33]. The generated mesh has 62.5 million elements.

Six main rectangular volumetric controls, one inside the other, were designed to refine the grid around the base geometry; other special refinement zones were defined to capture the wheel surface of the six tires. Several prismatic layers were added around the whole vehicle to correctly predict the flow in the boundary layer. 
Table 2-2. Grid independency as percentage of the drag and side coefficient obtained for the selected mesh of 62.5 million of elements.

\begin{tabular}{|c|c|c|}
\hline Millions of elements & \% Cx & \% Cy \\
\hline 39.7 & $3.51 \%$ & $4.55 \%$ \\
\hline 48.5 & $0.84 \%$ & $0.52 \%$ \\
\hline 62.5 & $/$ & $/$ \\
\hline 80.4 & 0.93 & $0.76 \%$ \\
\hline
\end{tabular}

Three fully developed layers around the tractor are added while five around the trailer. The cells size around the truck is $0,0015 \mathrm{~m}$ and the $\mathrm{y}+$ value is around 30. In Figure 2-3 some mesh details are shown, assessing the good mesh quality and the reproduction of the prismatic cell layers all over the truck and trailer surface.
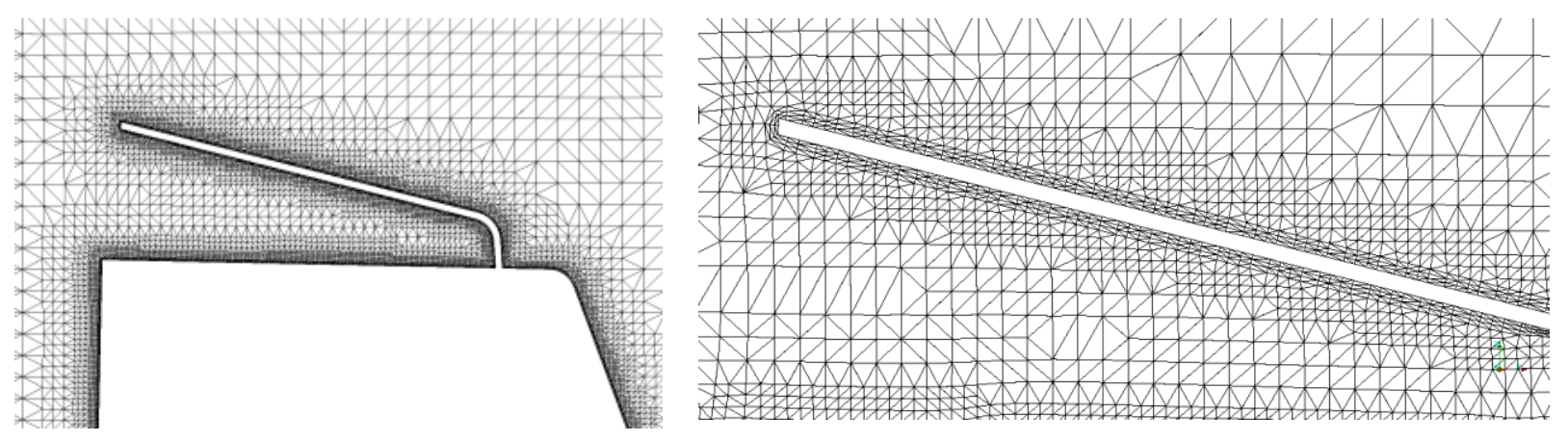

Figure 2-3. Mesh detail on the tractor top.

Time invariant incompressible RANS equations were solved using the simpleFoam [34] standard solver and for the two equations k- $\omega$ the SST turbulence model was used. The second-order upwind discretization scheme was used and the SIMPLEC algorithm was adopted for coupling pressure and velocity [35]. According to [36], the overturning of the HGV may occur when the vehicle itself experienced a yaw angle between $20^{\circ}$ and $40^{\circ}$ depending on the heavy truck load and speed.

In this work, it is decided to simulate a simple driving condition in which a HGV is travelling in straight road with a constant lateral wind in space and time with a yaw angle of $30^{\circ}$.

The inlet velocity was set at $30 \mathrm{~m} / \mathrm{s}$ imposing a yaw angle of $30^{\circ}$; the ground had the same velocity of the inlet. This wind velocity generated a Reynolds Number higher than $7 \cdot 10^{6}$ using the vehicle length. The simulations were carried out in scale 1:10.

The truck was considered stationary, while the flow and the ground had the inlet velocity. The wheel of the truck and the trailer are stationary as they are in the wind tunnel experiment used to valid the numerical model.

Following the work of Stapleford and Carr [37] on a fully exposed wheel, the $\mathrm{C}_{Z}$ and the $\mathrm{C}_{\mathrm{X}}$ given by a rotating wheel with zero ground clearance were found to be approximately those of a fixed wheel with small ground clearance, even lower in this case where most of the wheels were shielded from the wheelhouse (in the tractor) and from each other (in the trailer). On the contrary, the absence of moving ground in the experiment influenced the flow field in the underbody of the vehicle.

This aspect can be noticed at the zero-yaw angle, when the yaw angle rises, the flow field around the vehicle is mostly affected by separation over the leading upper edge of the trailer, not from the underbody such that the effect of rotating/stationary wheels can be neglected for the porpoise of this study.

The air velocity was setup in the $\mathrm{x}$ and $\mathrm{y}$ direction in both the inlet and right side (where the $\mathrm{x}$-component is the truck speed and the $\mathrm{y}$-component is the cross-wind velocity), while zero pressure was selected in the outlet and left side. The slip wall was used for the top. In order to speed up the 
simulation convergence and the computational time, the steady state simulations were initialized with the potential solver potentialFoam [34].

RANS simulations were run until the convergence of the aerodynamic forces was reached (oscillation of the residuals and of the aerodynamics forces around $1 \%$ ).

When performing time invariant simulations, the Detached Eddy Simulation (DES) with the two equations $\mathrm{k}-\omega$ the SST turbulence model was used; transient equations were solved using the standard pimpleFoam solver [34].

DES simulations were performed using a time step suitable for the mesh size around the vehicle, paying attention to keep the Courant number below 1. The influence of different time steps was studied and the most suitable value for the time step was $2 * 10^{-5} \mathrm{~s}$. Unsteady calculations were started from the solution of the flow in the steady-state simulation, it was possible to obtain a statistically stable solution in 5,000 time-steps. Lift, drag, side force fluctuated no more than \pm 5 percent of the average value. The time average was performed analyzing 25,000 time-steps after reaching the convergence in the shedding vortices.

The numerical simulations were in accordance with the SAE Standard J2966 [33].

\subsection{Validation of the numerical model}

The numerical model introduced in section 2.2 was validated with previous author wind tunnel test reported in [23]. In this section, the main results of the wind tunnel campaign are summarized to ensure the reliability of the numerical model. The aerodynamic coefficients obtained from steady state CFD simulations were compared with the experimental ones in Figure 2-7 for yaw angle from $0^{\circ}$ to $50^{\circ}$.

To evaluate the aerodynamic coefficients of the vehicle and set up the CFD model, experimental tests were performed using a flat ground scenario (see Figure 2-4). The flat ground scenario consisted of a $2.00 \mathrm{~m}$ wide, $0.03 \mathrm{~m}$ thick, and $4.00 \mathrm{~m}$ ground board, whose upper surface was at a height of 0.35 $m$ above the wind tunnel floor to obtain a block profile for the mean wind speed blowing on the model. The vehicle model was placed at $1.57 \mathrm{~m}$ from the leading edge, as shown in Figure 2-4. Aerodynamic forces acting on the vehicle were measured using a 6-component industrial dynamometric balance. The dynamometric balance was placed inside the vehicle model, near its center of gravity (COG) as shown in Figure 2-5 and Figure 2-6.

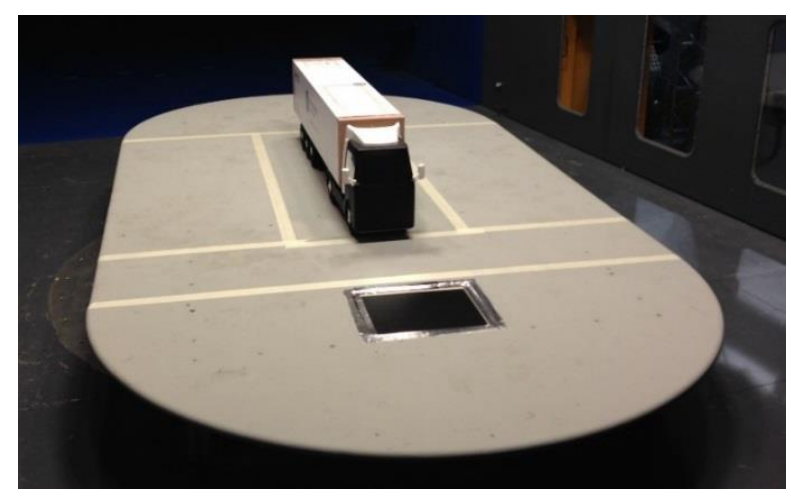

Figure 2-4. HGV 1:10 scale model used for wind tunnel test (see previous author's works [23] for more details).

Maximum errors of $2 \%$ for the $\mathrm{C}_{X}, 7 \%$ for the $\mathrm{C}_{Y}$ and $5 \%$ for the $\mathrm{C}_{Z}$ were measured. From the previous author's works [23], the wind tunnel tests have reasonable results until a yaw angle of $30^{\circ}$ $35^{\circ}$. The used ground board generates a Boundary Layer (BL) on the top of it lower than $5 \mathrm{~cm}$ in front wind. During the test, the rotating table of the wind tunnel rotates with the ground board and the vehicle model itself. Rotating the ground board, it changes also its aerodynamic, increasing the height 
of the BL on the ground board, until, at certain yaw angle, the height of the BL is comparable with the height of the vehicle model.

For higher yaw angle than $30^{\circ}$ the height of the boundary layer on the surface of the ground board, located at the bottom of the heavy truck, is not considered suitable to achieve proper results.

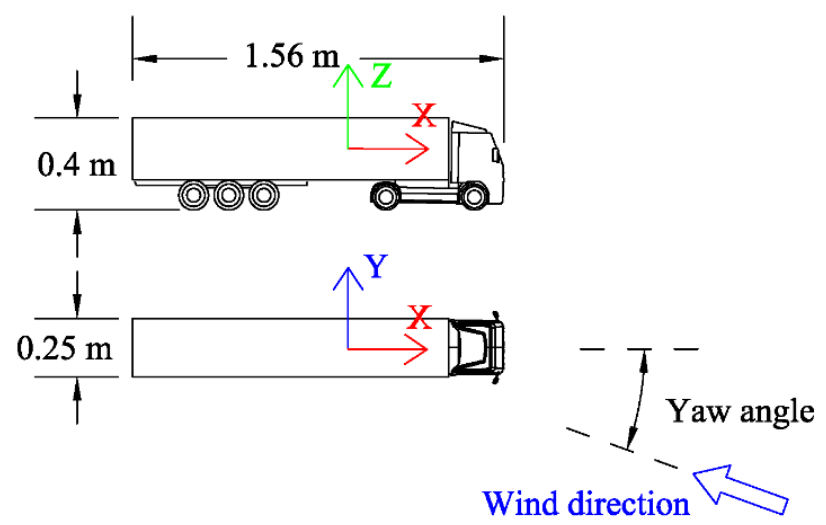

Figure 2-5. Reference system for aerodynamic forces calculation and truck dimension (dimensions are reported in wind tunnel scale).
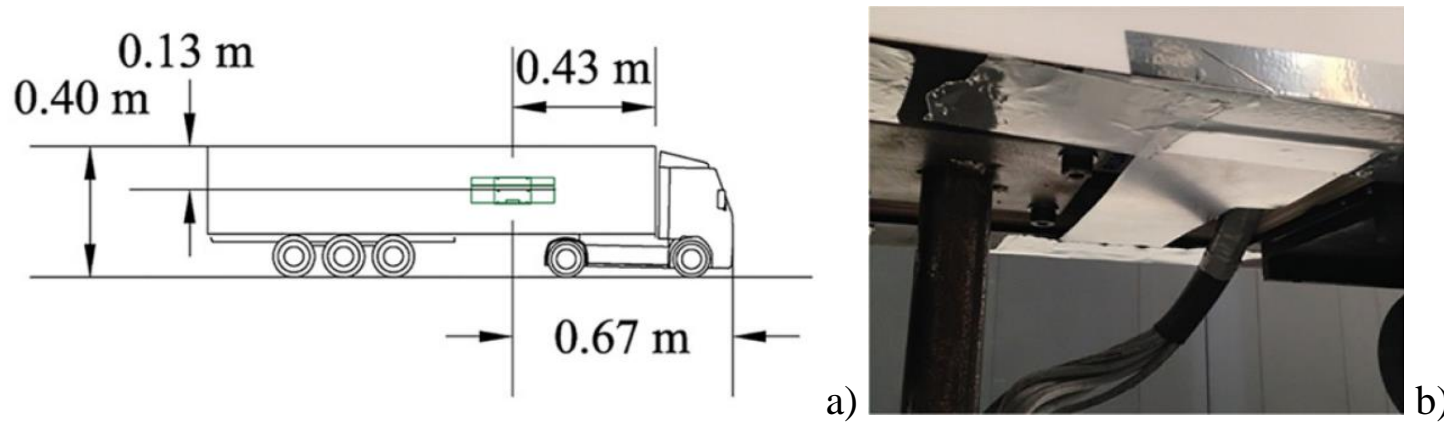

Figure 2-6. a) Force balance inside the trailer; and b) detail of the connection between the truck and ground.

The measured experimental $\mathrm{C}_{X}$ and the calculated numerical one from steady state simulation are consistent with each other. Small differences between numerical and experimental results can be seen in the slope of the curve of the side force coefficient $\mathrm{C}_{Y}$ over the yaw angle. A good correspondence of the results was observed also for the lift force coefficient $\mathrm{C}_{Z}$; in particular, it is possible to visualize how the lift coefficient changes the sign from negative to positive when the yaw angle increases from $0^{\circ}$ to $10^{\circ}$ in both the wind tunnel tests and the CFD.
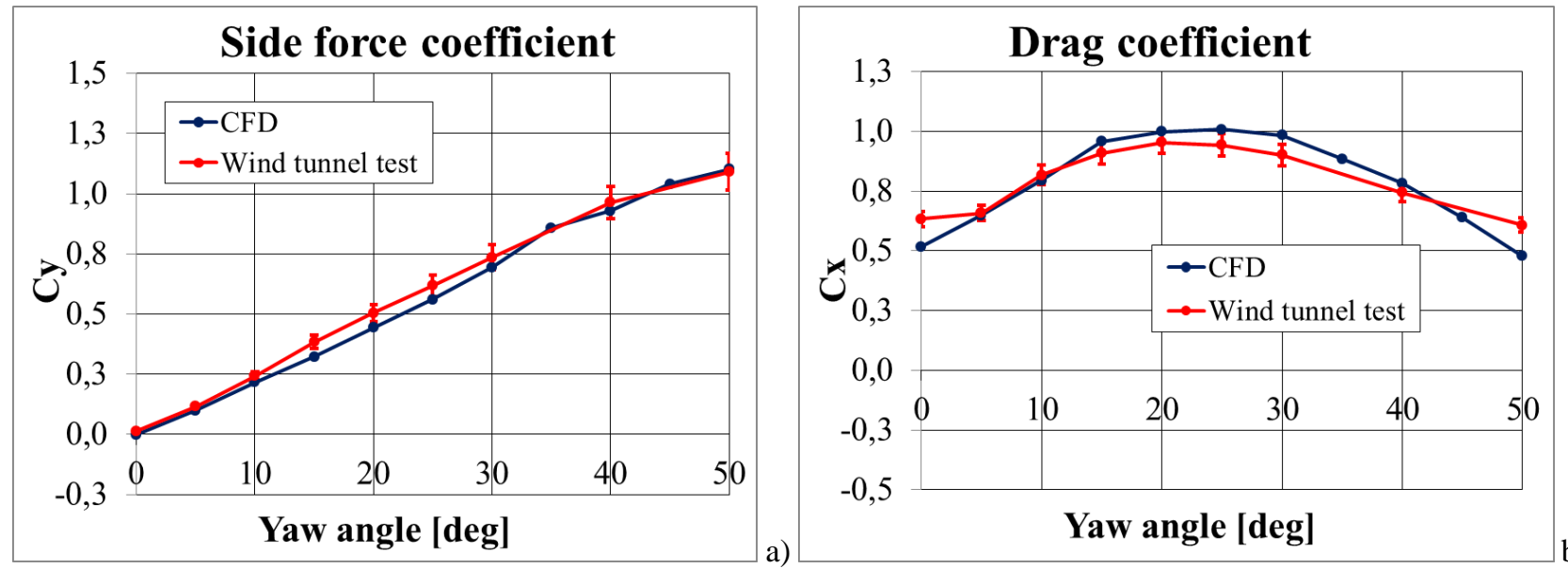


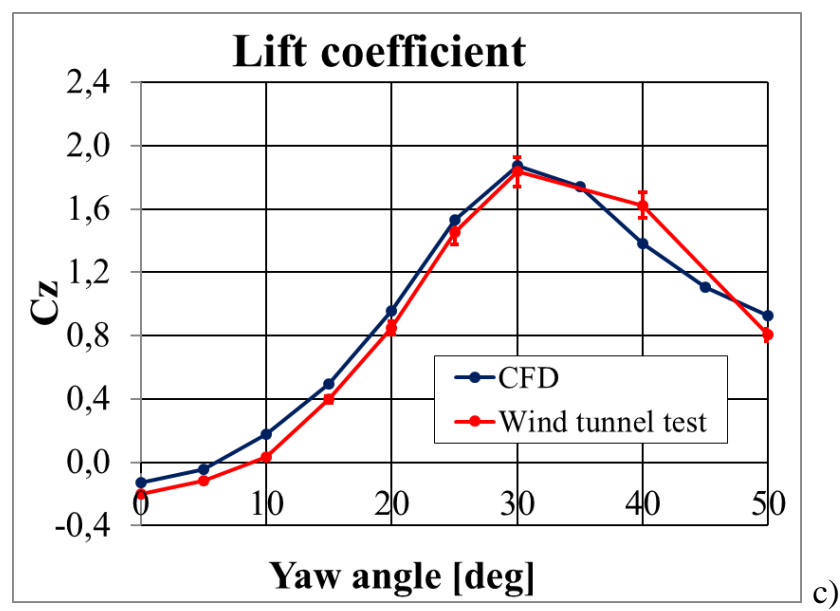

Figure 2-7. Aerodynamic force coefficient as a function of the wind yaw angle: a) Side force coefficient, b) drag coefficient, c) lift coefficient.

\subsection{Overturning analysis}

As mentioned in the introduction, a first solution to reduce overturning risk lies in designing fences and a lateral shield to be placed both at the edges of the bridge and close to the tower, shielding the vehicle from cross-wind. However, it is also possible to optimize the aerodynamic response of the vehicle. In this work, three main ways were used and compared:

$>$ Changing of the shape of the trailer.

$>$ Vortex Generators (VGs) installed on the leading edge of the trailer.

$>$ Front-rear trailer device installed along the sides/top of the trailer.

The performance of the tested strategies to mitigate the risk of overturning was compared computing the overall aerodynamic forces acting on the vehicle (considering pressure and the viscous effect); the overturning moment was calculated with reference to the axis of rotation of the HGV in Figure 2-9. The target vehicle was divided into 6 slices as shown in Figure 2-8. Slice from 1 to 4 had a height of $0.5 \mathrm{~m}$ starting from the top of the trailer. Slice 5 include the remain part of the trailer (around 0,64 $m$ ), while the rest of the truck was located in slice 6 .

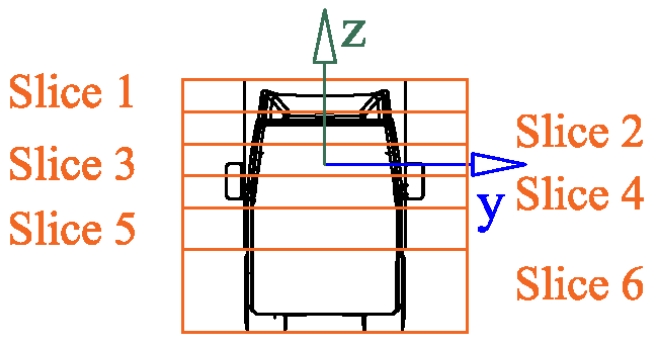

b)

\begin{tabular}{|c|c|c|}
\hline slice1 & slice2 & slice3 \\
\hline $13.28 \%$ & $27.69 \%$ & $42.29 \%$ \\
\hline slice4 & slice5 & slice6 \\
\hline $57.08 \%$ & $76.23 \%$ & $100 \%$ \\
\hline
\end{tabular}

a)

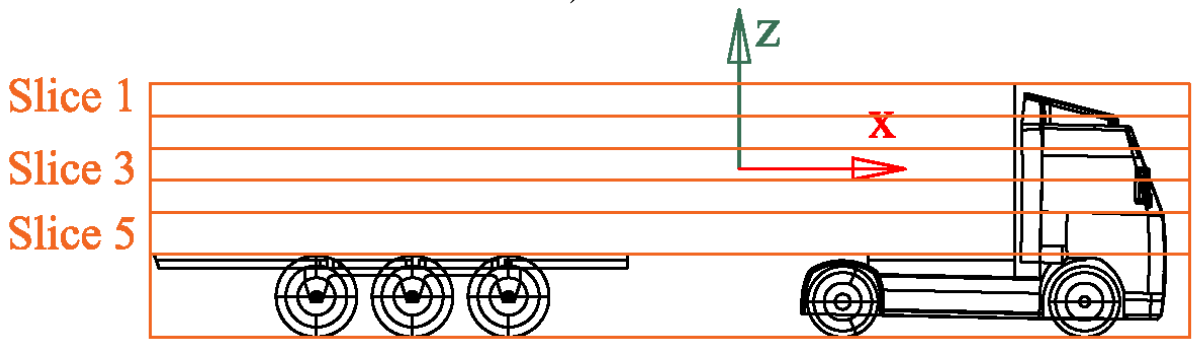

Slice 2

Slice 4

Slice 6

Figure 2-8. Division of the truck in slices: a) frontal view, b) cumulative lateral area of each slice as percentage of the total lateral area $\left.A_{\text {lat }}, c\right)$ later view. 
The lateral area of each slice it is reported in Figure 2-8. Side force Fy,i and lift force Fz,i were computed for each slice integrating the pressure over the vehicle surface in the $\mathrm{y}$ and $\mathrm{z}$ directions. The viscous effects were neglected due to their low influence on the overall aerodynamic forces (below 1\% in this kind of phenomena).The overturning moment was computed for each i-slice from point $\mathrm{O}$ in the next figure. The distances $\mathrm{B}, \mathrm{i}$ and $\mathrm{H}, \mathrm{i}$ are the distances of the side force and lift force acting on the i-slice.

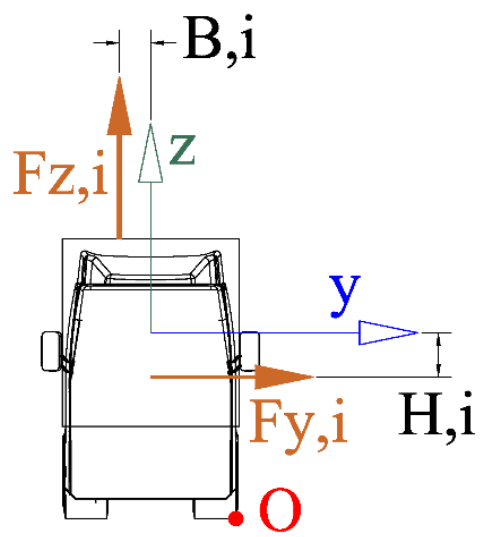

Figure 2-9. Lift and side force acting on the HGV.

\subsection{Changing of the shape of the trailer}

When the HGV is subject to cross-wind, there is a strong flow-field component in the y direction (see Figure 2-9). The flow, approaching the side of the vehicle along the y direction, was deviated over the surface of the side of the truck in the $\mathrm{z}$ direction: some of said flow moved down, and some moved up. On the top corner of the trailer, the flow separated generating high turbulence. The simplest way to reduce the side force acting on the heavy truck was to change the shape of the trailer from the standard rectangular one, making the corner between the top and the side of the trailer as smooth as possible.

Three different trailer shapes were tested to ensure a smoother transition of the flow from the side of the trailer to the top: rounded corner, inclined corner at $45^{\circ}$ and corner cut.

All the modifications to the shape of the trailer proposed reduced the trailer load capacity. Different sizes of the parameter " $\mathrm{R}$ " from $0.1 \mathrm{~m}$ to $0.3 \mathrm{~m}$ were used to evaluate the performance of the tested shape in reducing the side force and the impact on the load capacity (see Figure 2-10).
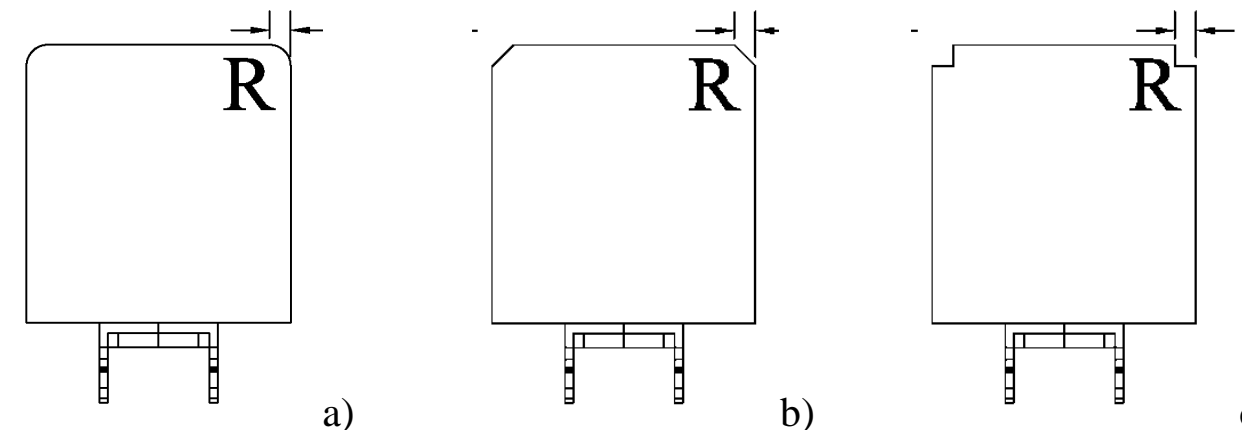

b)

c)

Figure 2-10. Changing of the shape of the trailer: a) Rounded corner, b) Inclined corner, c) Corner cut.

\subsection{Vortex Generators (VGs) installed on the leading edge of the trailer.}

Heavy truck geometry for studying VGs 
There is a great difference in scale between VGs and the surface on which they are installed: normally they have a size comparable with the height of the BL over the surface on which they are installed. Furthermore, VGs can be used in matrix arrays mainly in co-rotating and counter-rotating VGs.

These two aspects impose for the numerical simulations to have a very fine mesh over the surface such it can compute the rotating or counter-rotating vortices downstream of the VGs. This makes the simulations so expensive to the point that they cannot be used. The computational domain was cut over the slices previously introduced maintaining constant, compared to the target simulation, the mesh quality in the remaining part of the domain (see Figure 2-8 and Figure 2-11), while the whole mesh sized reduced according to number of slices considered in the simulation. As an example, in Table 2-3, "Slice 1" represent the simulations in which the ground was located at the bottom of the slice 1, while in "Slice 2", the ground was positioned on the bottom of slice 2 . The selected simplified truck was provided with a half-length trailer compared to the target vehicle and the ground was located on the bottom of the slice 4. Figure 2-11 shows the simplified truck over the target one with the blue hatch.

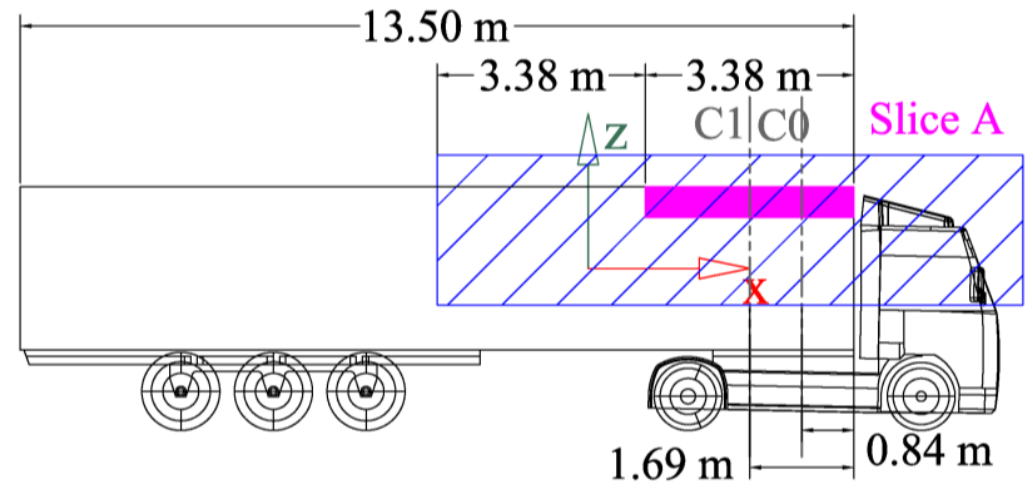

Figure 2-11. Comparison between the target vehicle and the simplified one.

The overall forces acting on the resized vehicles were different, as well as the wake generated in the rear part of them (see Figure 3-3 and Figure 3-4). On the contrary, they had the same aerodynamic response (forces, vortices and separation) on slice A, on the top of the trailer (see Figure 2-11). Slice A is one quarter of the slice 1, the part of the vehicle where the separation started, that is the top of the trailer responsible for the high turbulence down-wind, the instability and the high overturning moment. The VGs studied in this work were positioned over the surface of slice A.

It should be marked that, the VGs in this paper, are being applied not on a surface experiencing gradual separation (such as a curved airfoil or roof of a vehicle - and therefore delaying separation as previously mentioned) but at the point of separation.

The mesh of the simplified truck had the same cell size of the mesh generated for the target vehicle. Nevertheless, it was $80 \%$ smaller compared to the target vehicle, strongly decreasing the computational cost.

Table 2-3. Aerodynamic forces acting on Slice A.

\begin{tabular}{|c|c|c|c|c|}
\hline & Cy Slice A & Cz Slice A & Cmx Slice A & Million of elements \\
\hline Target truck & 0.02 & 0.79 & 0.28 & 62.50 \\
\hline Slice 1 & 0.02 & 0.25 & 0.14 & 11.00 \\
\hline Slice 2 & 0.02 & 0.48 & 0.24 & 14.60 \\
\hline Slice 3 & 0.03 & 0.65 & 0.30 & 18.00 \\
\hline Slice 4 & 0.03 & 0.77 & 0.33 & 21.60 \\
\hline Simplified truck & 0.03 & 0.75 & 0.31 & 13.50 \\
\hline
\end{tabular}


Figure 2-12, compares the magnitude of the vorticity computed at plane $\mathrm{C} 0$ and $\mathrm{C} 1$, reported in Figure 2-11. $\mathrm{U}_{\infty}$ is the free-stream velocity, while $\mathrm{h}$ is conventionally chosen as the height of the vortex. There is a general agreement between the vortices structure on the top front separation between the two vehicle models at both $\mathrm{C} 0$ and $\mathrm{C} 1$ planes, even if the vortex structure in the simplified HGV, seems to be bigger in the wind direction than in the real case. If we look at Figure 2-11, we may note that the flow field hitting the side of the target vehicle can move over and under it, while in the simplified one it can pass only on the top (the bottom part of the vehicle is the ground of the domain). As a consequence, the vortex on the top of the vehicle is more developed in the wind direction. On the other hand, the aerodynamic forces computed over the vehicle surface, on the slice A, were almost the same as those of the target vehicle as the height for the simplified truck was selected as optimum to reduce the mesh size and correctly reproduce the flow field over the vehicle.

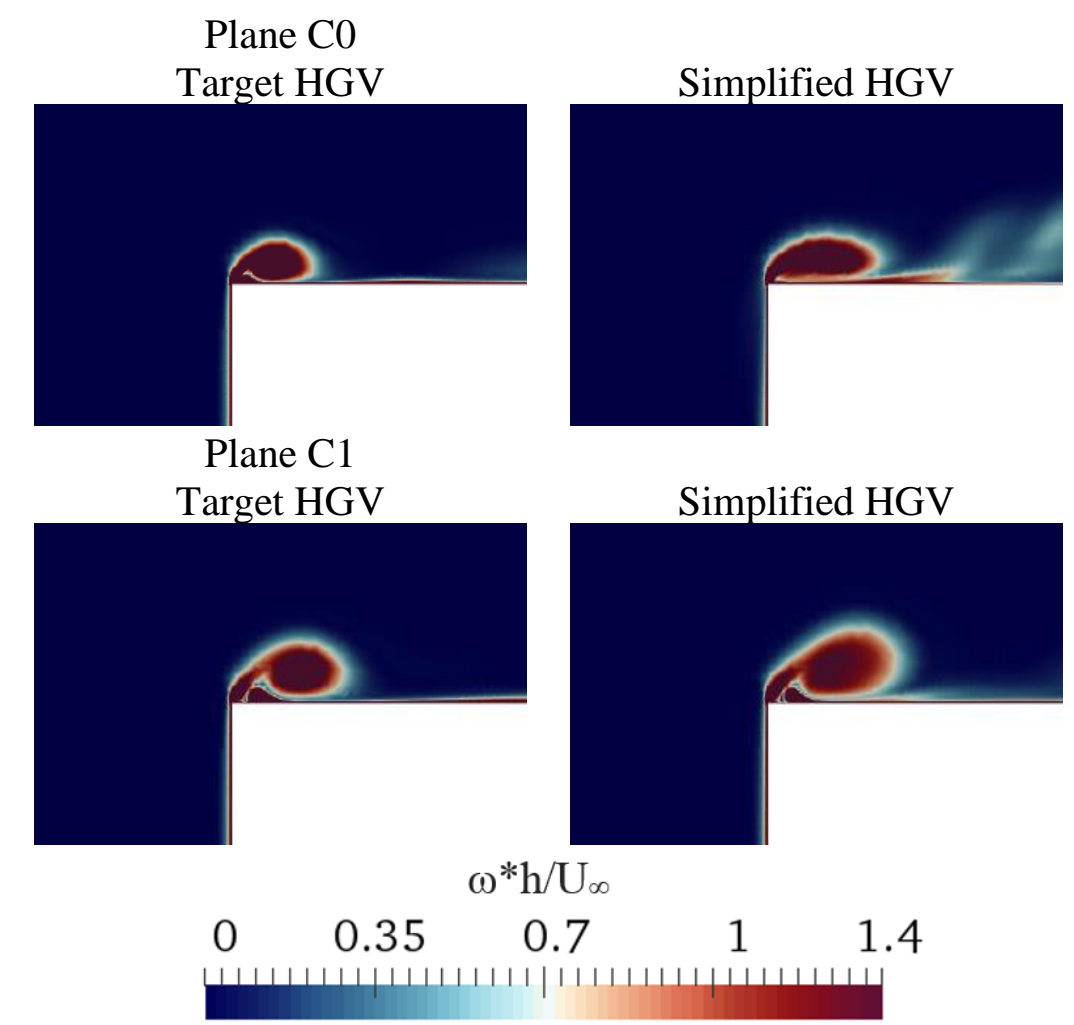

Figure 2-12. Comparison of the magnitude vorticity between the target vehicle and the simplified one.

Figure 2-13 shows the isovorticity of magnitude $1000 \mathrm{l} / \mathrm{s}$ for the two tested vehicle models. The main differences between the two HGVs were generated from the wake of the upwind side window. In fact, its wake downwind (see Figure 2-13-a), for this particular yaw angle, interacted with the separation on the top/front of the trailer.

This interaction was also responsible, to a lesser extent, for the higher vorticity and fluctuation on the top/front of the trailer, as previous mentioned and clearly visible in Figure 2-13, as well. These differences are not considered an issue for the purpose of this work, as it is mainly focused on controlling the separation on the top/side of the trailer.

\section{Vortex Generator Tested}

It was decided to make a matrix array on VGs on Slice A of $10 \mathrm{VGs}$ positioned on the top separation leading-edge in a length of $2 m$, as shown in red, in Figure 2-14 in agreement with [32]. The generated mesh had a size of around 40 million elements. 
The tested VGs were made from the delta wing shape showed in Figure 2-15-a. The first kind of device was a single delta wing shape, with a rotation of $15^{\circ}, 30^{\circ}$ and $45^{\circ}$ with reference to the positive $\mathrm{x}$ axis (Figure 2-15-b). The second one was a double delta wing shape (Figure 2-15-c): the delta wings were merged along Size of $100 \mathrm{~mm}$ and inclined of $15^{\circ}$ and $30^{\circ}$, the generated devices were then inclined $15^{\circ}$ and $30^{\circ}$ along the positive $\mathrm{r}$ axis.

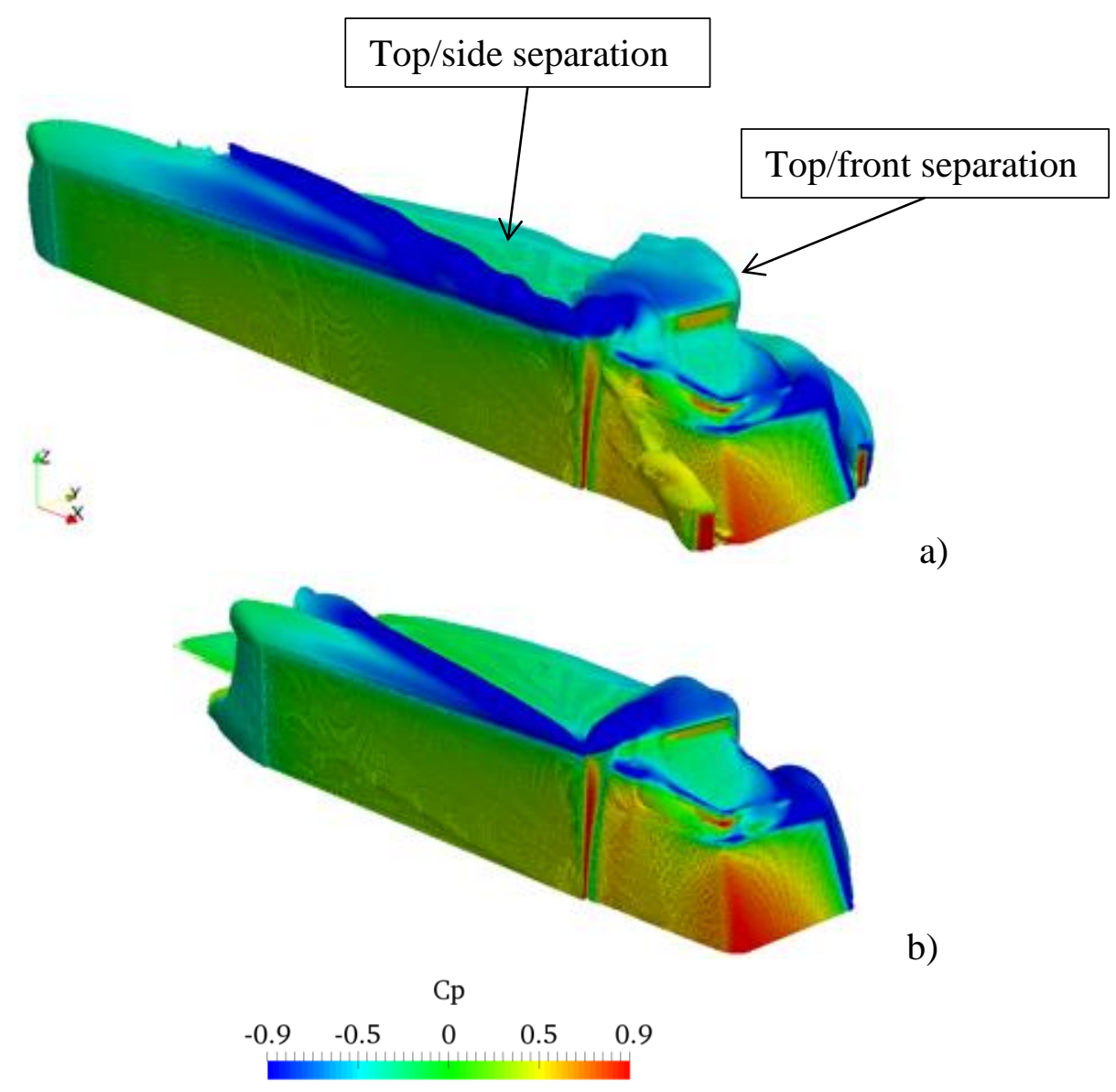

Figure 2-13. Comparison of the isovorticity colored with the pressure coefficient for the vehicle models: a) target truck, b) simplified truck.

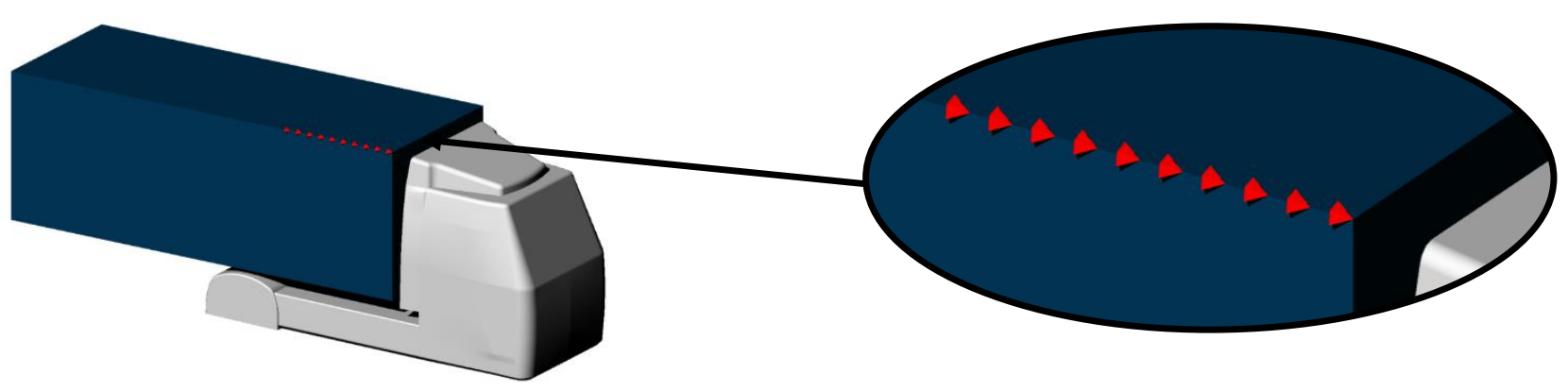

Figure 2-14. VGs location on the trailer.

The third kind of VGs was a double delta wing shape (Figure 2-15-d): the delta wings were merged along Size $b$ with a rotation of $15^{\circ}, 30^{\circ}$ and $45^{\circ}$. The last device was a single delta wing shape positioned in a standard co-rotating matrix array. As evidenced in Figure 2-15, the VGs were scaled 10:1 on the HGV surface to better visualize the differences between the various devices. In Figure $2-16$, the VGs, previously introduced are illustrated over the trailer. 
Table 2-4. Geometric characteristics of the VGs.

\begin{tabular}{|c|c|c|c|c|c|}
\hline VGs & $\begin{array}{c}\text { \# of delta } \\
\text { wing }\end{array}$ & $\begin{array}{c}\text { Rotation around } \\
\text { the } \mathbf{x} \text { axis }\end{array}$ & $\begin{array}{c}\text { Rotation around } \\
\text { the r axis }\end{array}$ & $\begin{array}{c}\text { Rotation around } \\
\text { the z axis }\end{array}$ & Reference \\
\hline 1 & Single & $15^{\circ}$ & $/$ & $/$ & Figure 2-15-b \\
\hline 2 & Single & $30^{\circ}$ & $/$ & $/$ & Figure 2-15-b \\
\hline 3 & Single & $45^{\circ}$ & $/$ & $/$ & Figure 2-15-b \\
\hline 4 & Double & $15^{\circ}$ & $15^{\circ}$ & $/$ & Figure 2-15-c \\
\hline 5 & Double & $30^{\circ}$ & $15^{\circ}$ & $/$ & Figure 2-15-c \\
\hline 6 & Double & $30^{\circ}$ & $30^{\circ}$ & $/$ & Figure 2-15-c \\
\hline 7 & Double & $15^{\circ}$ & $/$ & $/$ & Figure 2-15-d \\
\hline 8 & Double & $30^{\circ}$ & $/$ & $/$ & Figure 2-15-d \\
\hline 9 & Double & $45^{\circ}$ & $/$ & $/$ & Figure 2-15-d \\
\hline 10 & Single & $/$ & $/$ & $30^{\circ}$ & $/$ \\
\hline
\end{tabular}
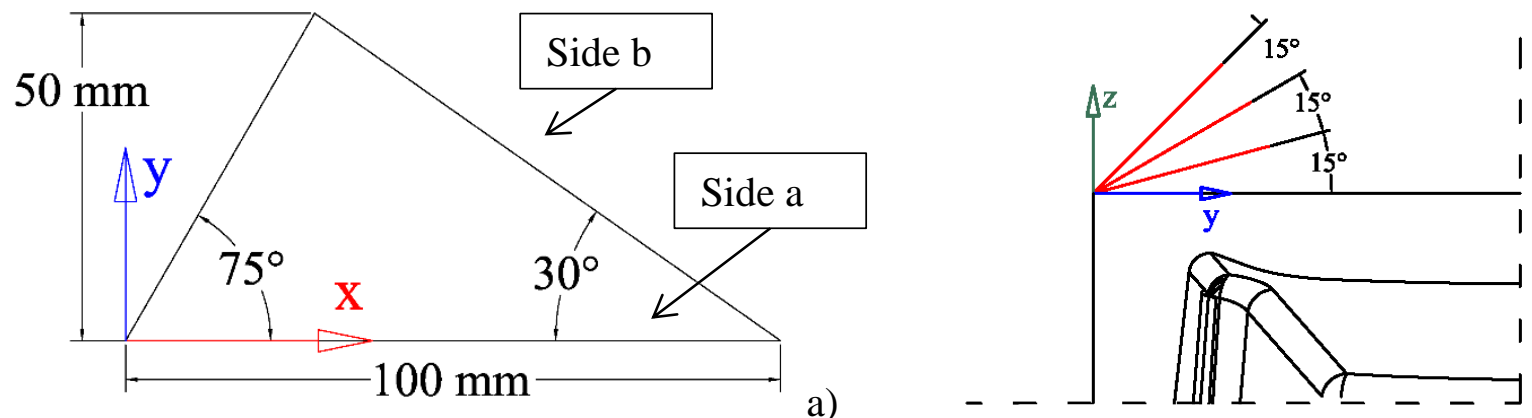

a)
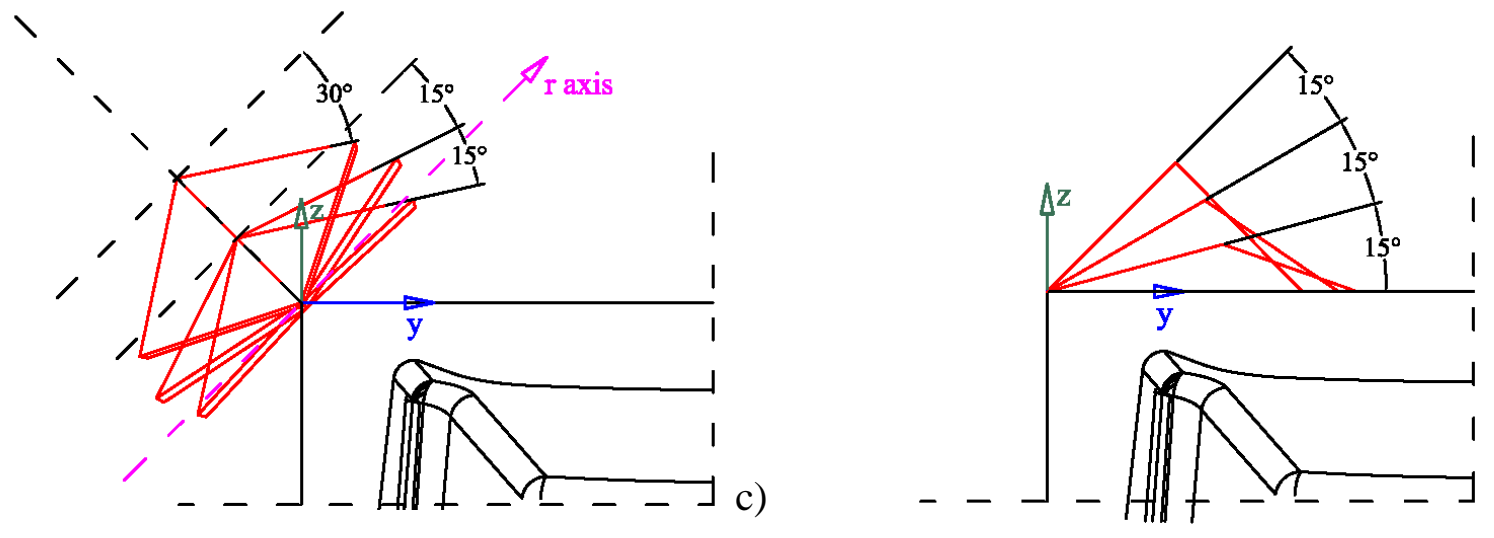

Figure 2-15. VGs delta wing shape, reported with red line, scaled 10:1 on the HGV surface.

\subsection{Front-rear trailer device installed along the sides/top of the trailer}

As reported in section 2.5, the simplest way to reduce the side force acting on the HGV was to change the shape of the trailer compared to the standard rectangular one, making the corner between the top and the side of the trailer as smooth as possible. In section 2.5, the smoother transition between the side and the top of the trailer was obtained reducing the load capacity of the trailer. In this section, the same results were obtained mounting external devices on the side/top of the trailer.

A crucial aspect of this strategy was to design devices that mitigate the overturning risk in cross-wind without increasing the drag of the vehicle in normal driving conditions (front-wind).

It was decided to test the performance of the Front-rear trailer device, previously developed and patent from the author's [9], [23], [38]. The device, apart to be installed on the front and rear of the trailer, 
was also mounted on the top sides of it: this configuration is called Lateral-top trailer device and it is divided into a lateral trailer device (device "H", see Figure 2-17) and a top trailer device (device "I", see Figure 2-17). The Lateral-top trailer device was developed to be fully integrated with the Frontrear trailer device, so as to couple both the drag reduction performance and the one for reducing the overturning risk.
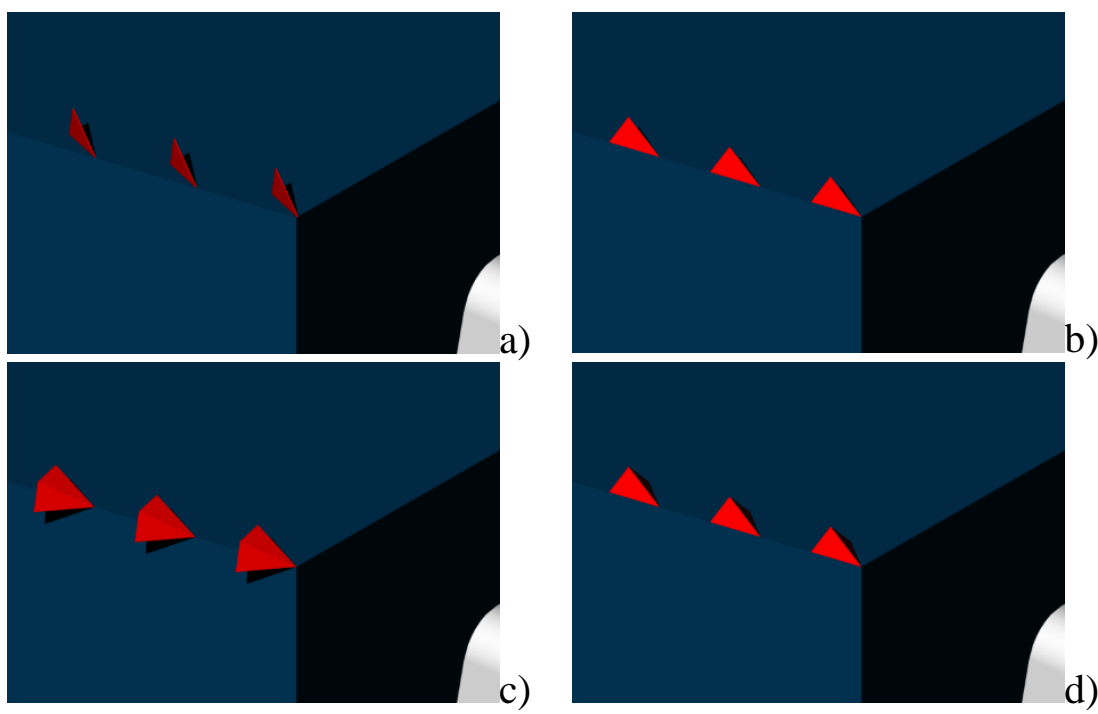

Figure 2-16. VGs 3D visualization: a) VG 10, b) VG 1-3, c) VG 4-6, d) VG 7-9.

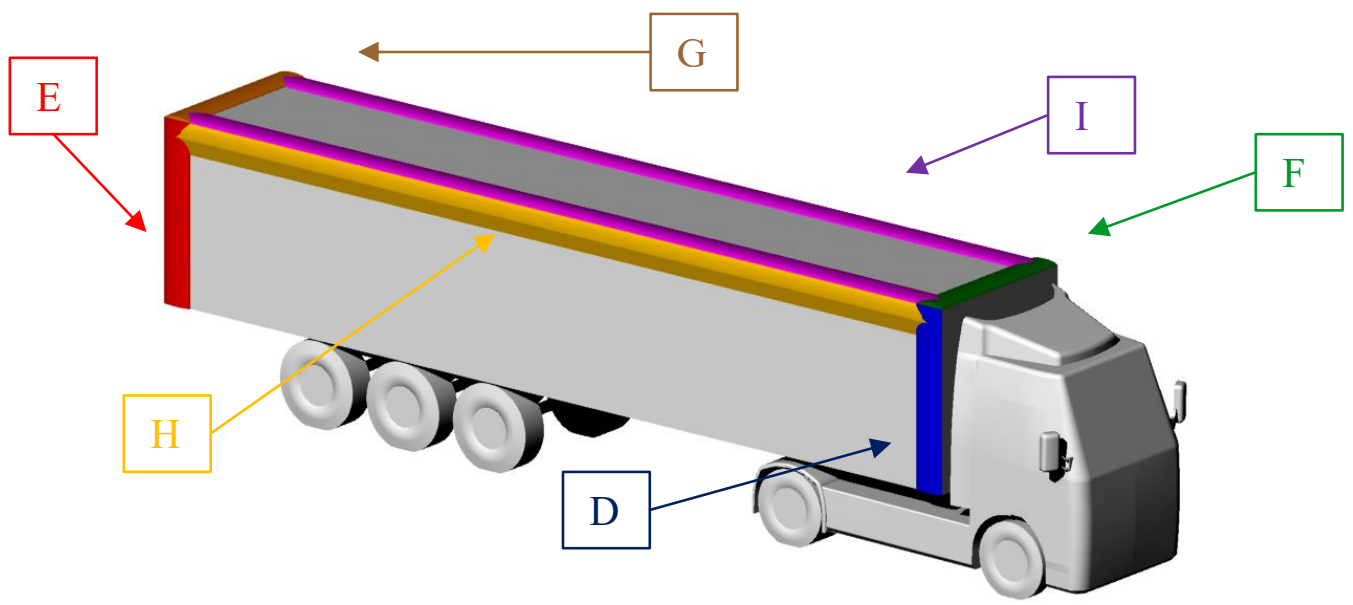

Figure 2-17. Front-rear devices installed along the sides/top of the trailer.

The shape of the devices is under patent, for more details on the [38], [23]. The semi-elliptic shape had a height $b=5 \mathrm{~cm}$ (full-scale) while the length a of $45 \mathrm{~cm}$ (full-scale) as reported in Figure 2-18.
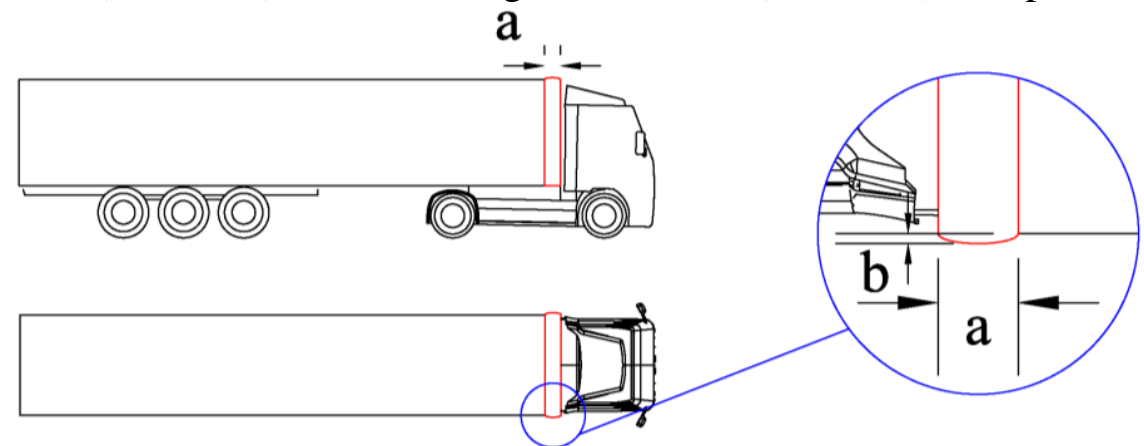

Figure 2-18. Front trailer device installed on the trailer. 


\section{Results and discussion}

\subsection{Target vehicle analysis}

Steady state analysis

The vehicle was divided into slices, as reported in section 2.4 and Figure 2-8, so as to visualize which areas affect the most the overall vehicle side force, lift and overturning moment.

Table 3-1 reports the percentage contribution of each slice over the total, while Table 3-2 show the percentage contribution of slice A over the total and over Slice 1. Slice 1, the top of the HGV, was responsible for almost $40 \%$ of the whole overturning moment, indicating this area as one of great interest to mitigate the overturn risk. Slice A was responsible for $30 \%$ of the whole Slice 1 overturning moment, and almost $11 \%$ of the total one. Furthermore, as highlighted in section 2.3 , the aerodynamic forces were computed integrating the pressure over the surface of the vehicle in the $y$ and $\mathrm{z}$ directions. The top/side separations on Slice A do not only influence the aerodynamics force on Slice A itself, but also on Slice 1 in its whole. The entire overturning moment contributed around $20 \%$ due to the lift force, while the rest was given by the side force.

Table 3-1. Contribution of each Slice to the entire HGV overturning moment, expressed as a percentage of the total.

\begin{tabular}{|l|c|c|c|c|c|c|}
\hline & Slice 1 & Slice 2 & Slice 3 & Slice 4 & Slice 5 & Slice 6 \\
\hline $\mathrm{Cy}$ & $7.49 \%$ & $13.49 \%$ & $15.20 \%$ & $15.89 \%$ & $20.34 \%$ & $27.58 \%$ \\
\hline $\mathrm{Cz}$ & $142.09 \%$ & $8.64 \%$ & $0.20 \%$ & $-0.73 \%$ & $-40.40 \%$ & $-9.81 \%$ \\
\hline $\mathrm{Cmx}$ & $39.67 \%$ & $20.75 \%$ & $17.58 \%$ & $14.53 \%$ & $0.73 \%$ & $6.74 \%$ \\
\hline
\end{tabular}

Table 3-2. Slice A contribution on the overturning moment.

\begin{tabular}{|l|c|c|}
\hline & Slice A over Slice 1 & Slice A over the total \\
\hline $\mathrm{Cy}$ & $29.75 \%$ & $2.23 \%$ \\
\hline $\mathrm{Cz}$ & $30.20 \%$ & $42.92 \%$ \\
\hline $\mathrm{Cmx}$ & $30.08 \%$ & $11.93 \%$ \\
\hline
\end{tabular}

\subsection{Changing of the shape of the trailer}

Steady state analysis

The simplest way to reduce the side force acting on a heavy truck is to change the shape of the trailer from the standard rectangular one, reducing the separation over the top of the trailer itself.

In order to ensure a smoother transition of the flow from the side of the trailer to the top, the following three trailer shapes were tested: rounded corner, inclined corner at $45^{\circ}$ and corner cut. All the modifications to the shape of the trailer proposed reduced the trailer load capacity. Different sizes, of length of the corner "R" from $0.1 \mathrm{~m}$ to $0.3 \mathrm{~m}$, were used to evaluate the performance of the tested shape in reducing the side force as impact on the load capacity. Table 3-3. Force coefficient reduction for the R Values higher than $0.3 \mathrm{~m}$ were not considered because the reduction of the load capacity would be too high. All the shapes of the trailer tested significantly reduced the vehicle overturning moment. Increasing the length of the $\mathrm{R}$ parameter, the reduction of the overturning moment increased in all of the tested shapes. Looking at Table 3-3, the rounded corner with $\mathrm{R}$ equal to $0.1 \mathrm{~m}$ reduced the side force around $13 \%$, while the lift increased by $6 \%$. As mentioned, the side force contribution on the entire overturning moment was 4 times higher than the lift one. Therefore, this kind of trailer reduces the whole vehicle overturning moment by $12 \%$. If the reduction of the load capacity is used 
as parameter to compare the different kinds of trailer shapes, for a load capacity reduction of $0.60 \%$ it is possible to reduce the overturning moment by $25 \%$ with a rounded corner, $18 \%$ with an inclined one, while for the corner cut it is around $10-13 \%$.

tested configuration compared to the target vehicle.

\begin{tabular}{|l|c|c|c|c|c|c|}
\hline & $\mathbf{R}$ & Cmx total & Cmx Slice A & Cy_tot & Cz_tot & $\begin{array}{c}\text { Reduction of load } \\
\text { capacity }\end{array}$ \\
\hline & {$[\mathrm{m}]$} & $\%$ & $\%$ & $\%$ & $\%$ & $\%$ \\
\hline Rounded corner & 0.1 & 12.77 & 31.17 & 13.22 & -6.64 & $0.07 \%$ \\
\hline Rounded corner & 0.2 & 20.25 & 41.13 & 17.96 & -2.43 & $0.26 \%$ \\
\hline Rounded corner & 0.3 & 24.75 & 40.36 & 20.14 & 3.93 & $0.59 \%$ \\
\hline Inclined corner & 0.1 & 9.54 & 27.13 & 10.44 & -3.69 & $0.15 \%$ \\
\hline Inclined corner & 0.2 & 17.58 & 58.28 & 14.20 & 3.88 & $0.61 \%$ \\
\hline Inclined corner & 0.3 & 20.81 & 40.19 & 14.68 & 9.12 & $1.36 \%$ \\
\hline Corner cut & 0.1 & 10.64 & 26.91 & 11.20 & -6.82 & $0.30 \%$ \\
\hline Corner cut & 0.2 & 18.02 & 32.81 & 12.69 & 5.38 & $1.21 \%$ \\
\hline Corner cut & 0.3 & 20.08 & 34.54 & 12.46 & 12.36 & $2.73 \%$ \\
\hline
\end{tabular}

At a constant volume reduction, the rounded corner was the one to show the highest performance with a limited reduction of load capacity below $1 \%$.In the iso-vorticity at planes $\mathrm{C} 0$ and $\mathrm{C} 1$ shown in Figure 2-11 and reported in Figure 3-1 and Figure 3-2, we can observe that in the case of the rounded corner the top/side vortex almost disappeared. Raising the $\mathrm{R}$ parameter, in the rounded corner, almost removed the vortices structure on the top corner of the trailer, in both the said planes, with high benefit in terms of overturning moment reduction. Plane $\mathrm{C} 0$ and $\mathrm{C} 1$ are placed at $1 / 8$ and $1 / 16$ of the trailer length from the front of the trailer (see Figure 2-11). The planes are chosen with a trial and error methodology to be representative of the differences in the flow structure in the top of the trailer when several trailer shapes or devices are tested.

The inclined corner seems to mitigate the vorticity, mostly postponing the separation from the side corner to the top corner, with benefit, for the force reduction, lower than the one obtained with the rounded corner. The corner-cut shape, that is normally used to mitigate the separation and forces acting on infrastructure such as the skyscraper or pylon of infrastructure, generated similar force and overturning moment reduction compared to the inclined corner at both $\mathrm{C} 0$ and $\mathrm{C} 1$ planes, even if the flow structure was completely different from the other corner changing.

As an example, looking at the corner cut with $\mathrm{R}=0.3 \mathrm{~m}$, we could observe a double separation occurring on the side corner and top corner, which would normally have generated higher forces and higher overturning moment.

Nevertheless, the illustrated planes are located in the front part of the trailer, where the separation starts. In the rear of it, the turbulence and the vortices structure were more developed, as can be observed in Figure 2-13. In this part of the trailer, the said configuration, corner-cut with $R=0.3 \mathrm{~m}$, reduced the separation over the top of the vehicle more efficiently than the rounded corner and the inclined one. In general, the rounded corner and the inclined one had higher performance in reducing the vortices structure in the front part of the trailer, while the corner cut in the rear one.

By contrast, the corner cut highly reduced the load capacity of the trailer compared to the other corners, and for this reason, it is the one with the lower chance to be adopted by manufacturers and heavy trucks users. 


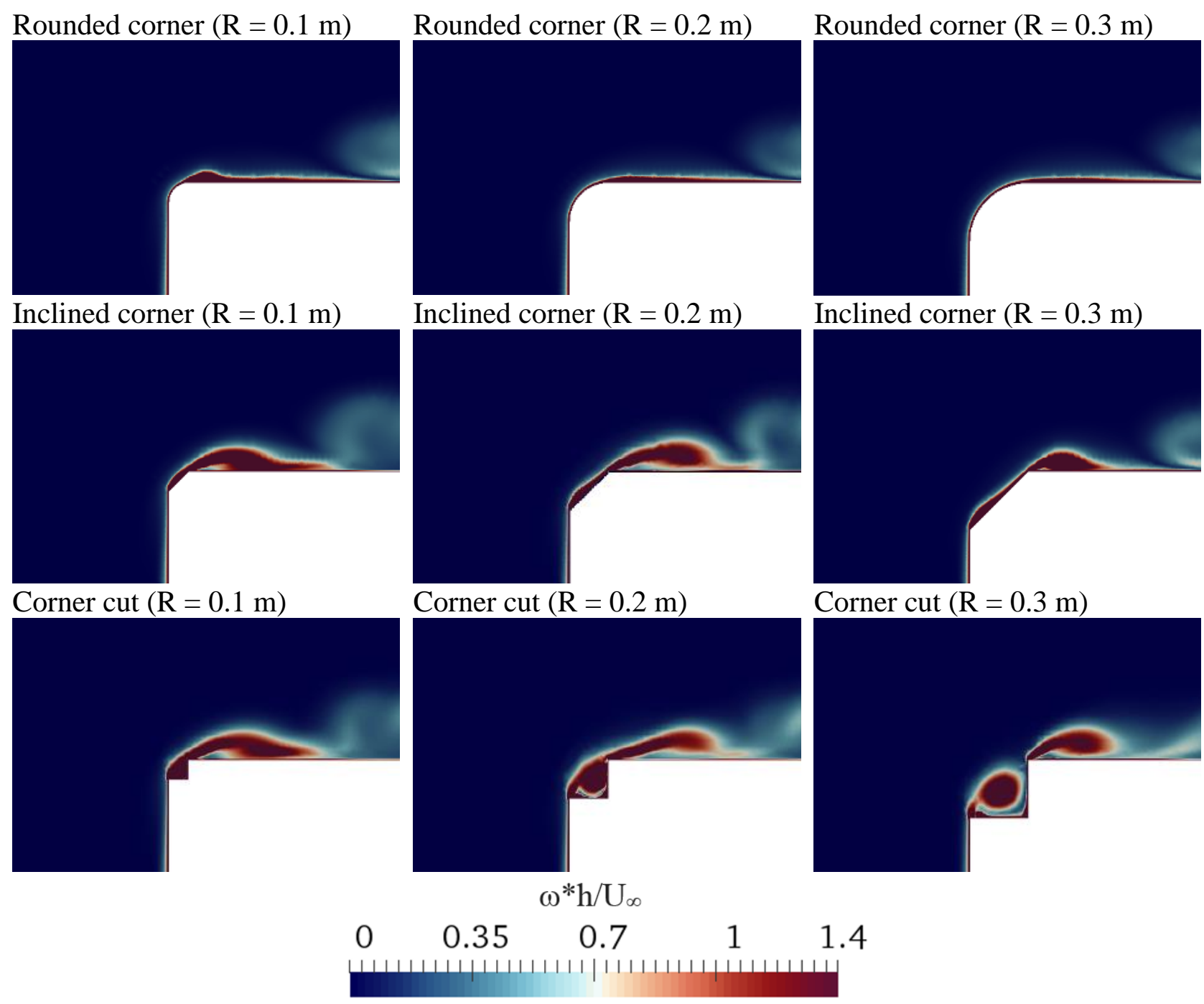

Figure 3-1. Magnitude vorticity on the plane $\mathrm{C} 0$ for the tested trailer shape. 


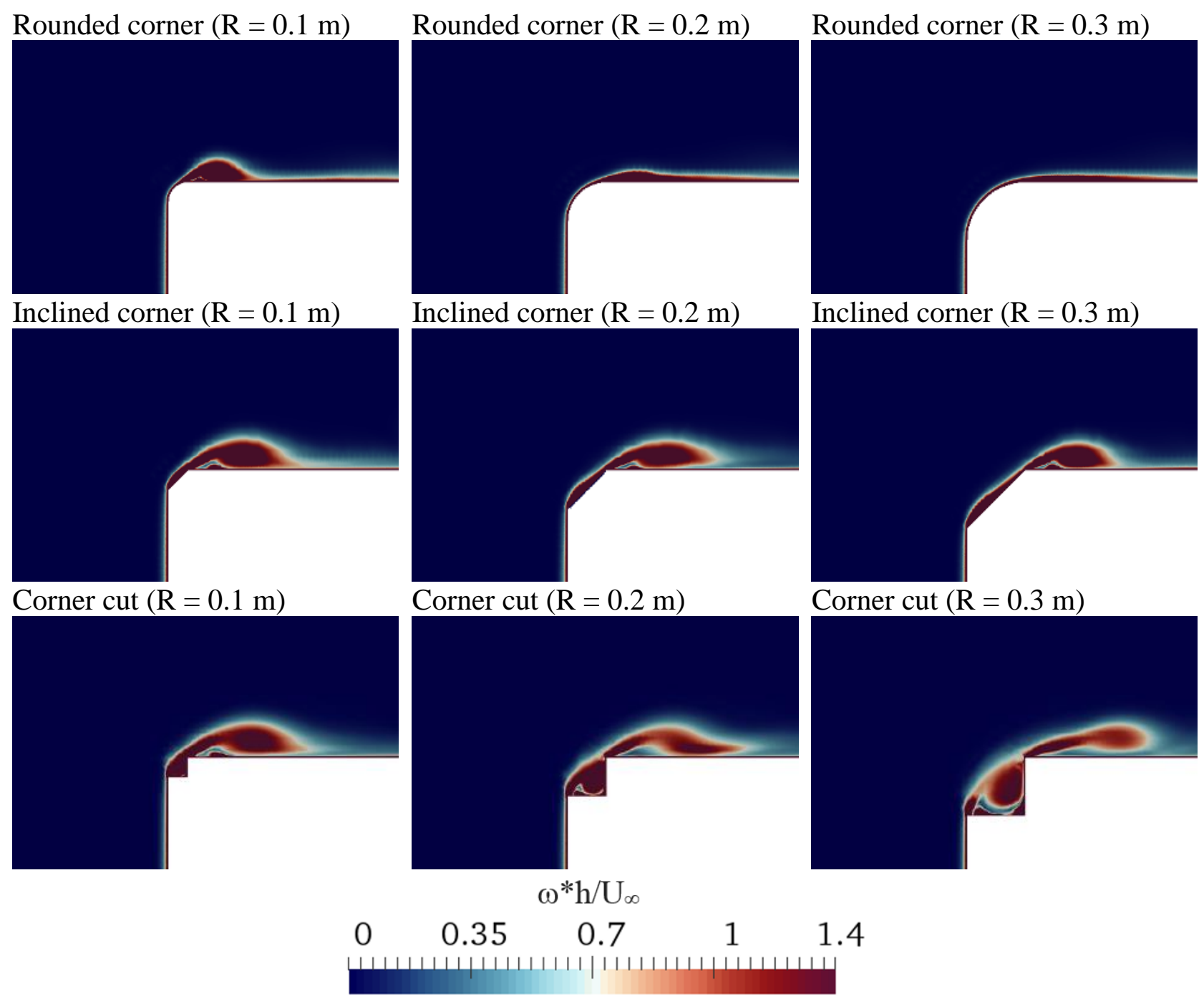

Figure 3-2. Magnitude vorticity on plane $\mathrm{C} 1$ for the trailer shape tested.

\subsection{Vortex Generators (VGs) installed on the leading edge of the trailer}

Steady state analysis

For the optimization of the VGs, the HGV used was the simplified truck previously introduced in section 2.6. The device proposed in Figure 2-15 and Figure 2-16 seems to have an overturning moment reduction not proportional to the design parameter reported. As an example, VG 1 reduced the HGV overturning moment by $1.43 \%$; when the rotation around the $\mathrm{x}$ axis increased from $15^{\circ}$ to $30^{\circ}, \mathrm{VG} 2$, the reduction of the overturning moment was almost negligible, while, when the rotation was around $45^{\circ}$, VG 3, the reduction of the overturning moment was similar to the one of the VG 1 . The same conclusions can be observed for the other VGs tested. Although the number of devices added onto the trailer was increased, the overturning moment did not significantly increase. As an example, when doubling devices VG 2 and VG 3 (instead of 10 devices in a length of $2.0 \mathrm{~m}, 20$ devices in a length of $4.0 \mathrm{~m}$ ), the reduction of the whole overturning moment for VG 2 was $1.13 \%$ instead of $0.3 \%$, while for VG 3, it was $0.53 \%$ instead of $1.41 \%$. The most promising tested VG was the single delta wing shape positioned in a standard co-rotating matrix array. Furthermore, comparing the performance of the VGs with the one of the changed shape of the trailer, the VGs did not seem a promising solution to mitigate the overturning risk. 
Table 3-4. Force coefficient reduction for the tested VGs compared to the simplified vehicle.

\begin{tabular}{|l|c|c|c|c|}
\hline & Cmx total & Cmx Slice A & Cy_tot & Cz_tot \\
\hline & $\%$ & $\%$ & $\%$ & $\%$ \\
\hline VG 1 & 1.43 & 2.43 & 0.89 & -0.26 \\
\hline VG 2 & 0.30 & 1.87 & 0.77 & -0.24 \\
\hline VG 3 & 1.41 & 2.17 & 0.75 & -0.08 \\
\hline VG 4 & 0.82 & 1.27 & 0.63 & -0.61 \\
\hline VG 5 & -1.11 & -0.92 & 0.28 & -0.57 \\
\hline VG 6 & -0.17 & 1.21 & 0.47 & -0.42 \\
\hline VG 7 & -0.45 & 0.12 & 0.48 & -0.37 \\
\hline VG 8 & 0.41 & 1.30 & 0.71 & -0.30 \\
\hline VG 9 & -0.22 & 0.65 & 0.32 & -0.31 \\
\hline VG 10 & 2.14 & 4.01 & 1.65 & -0.08 \\
\hline
\end{tabular}

It seems like the separation occurring on the top-side of the trailer is too massive to be controlled with VGs. In Figure 3-3 and Figure 3-4, the iso-vorticity at planes $\mathrm{C} 0$ and $\mathrm{C} 1$ is shown and compared with the simplified HGV. We may notice, in any of the presented VGs, a change in the vortices structure on the top of the trailer. The device introduces a vortical structure in the boundary layer (BL) mixing the high-momentum flow on the external layer of the BL with the low-momentum flow over the surface. On the other hand, as also pointed out in Table 3-4, there was no marked reduction of aerodynamic forces and of the overturning moment to justify the use of this device. It appears that the separation on the top corner of the trailer is too massive to allow a reattachment of the energized flow downwind the VGs. It can also be observed that the slightly differences existing between the vortices structure are mostly due to the different kind of VG (VG 1-3, VG 4-6, VG 7-9 and VG 10) and not to the parameter selected for their geometry optimization. The massive separation occurring on top of the trailer will potentially require more invasive VGs than the ones developed in this work. More invasive devices exceed the maximum vehicle size permitted by the regulations in force suggesting, once again, that there were more efficient strategies to reduce the overturning risk of the heavy truck.

VG 1

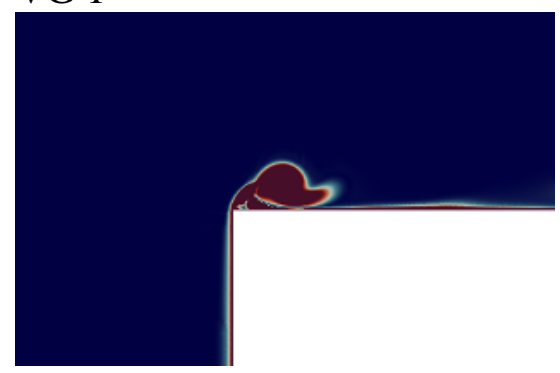

VG 4

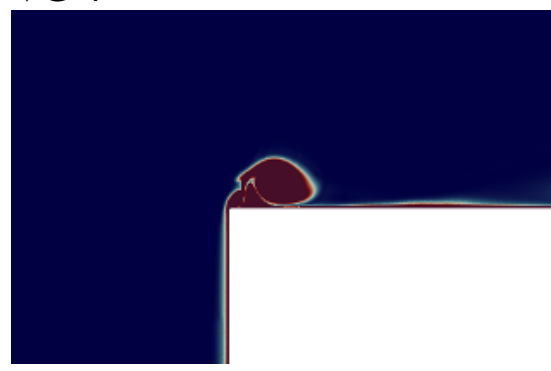

VG 2

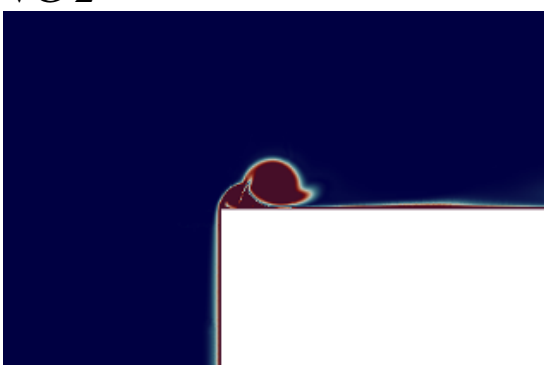

VG 5

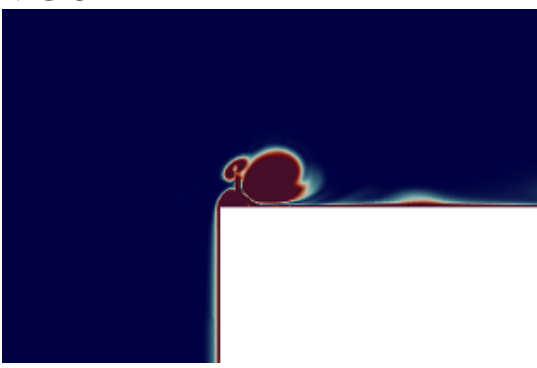

VG 3

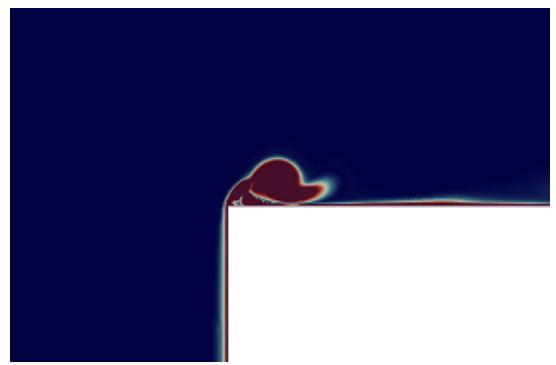

VG 6

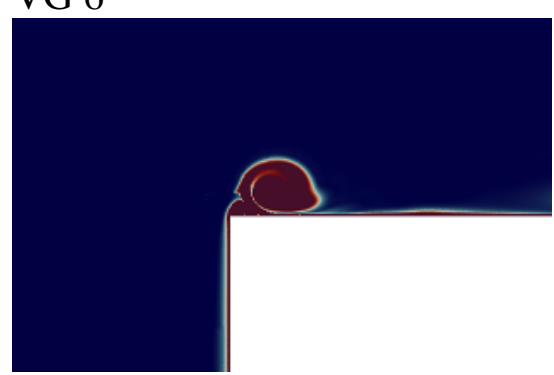




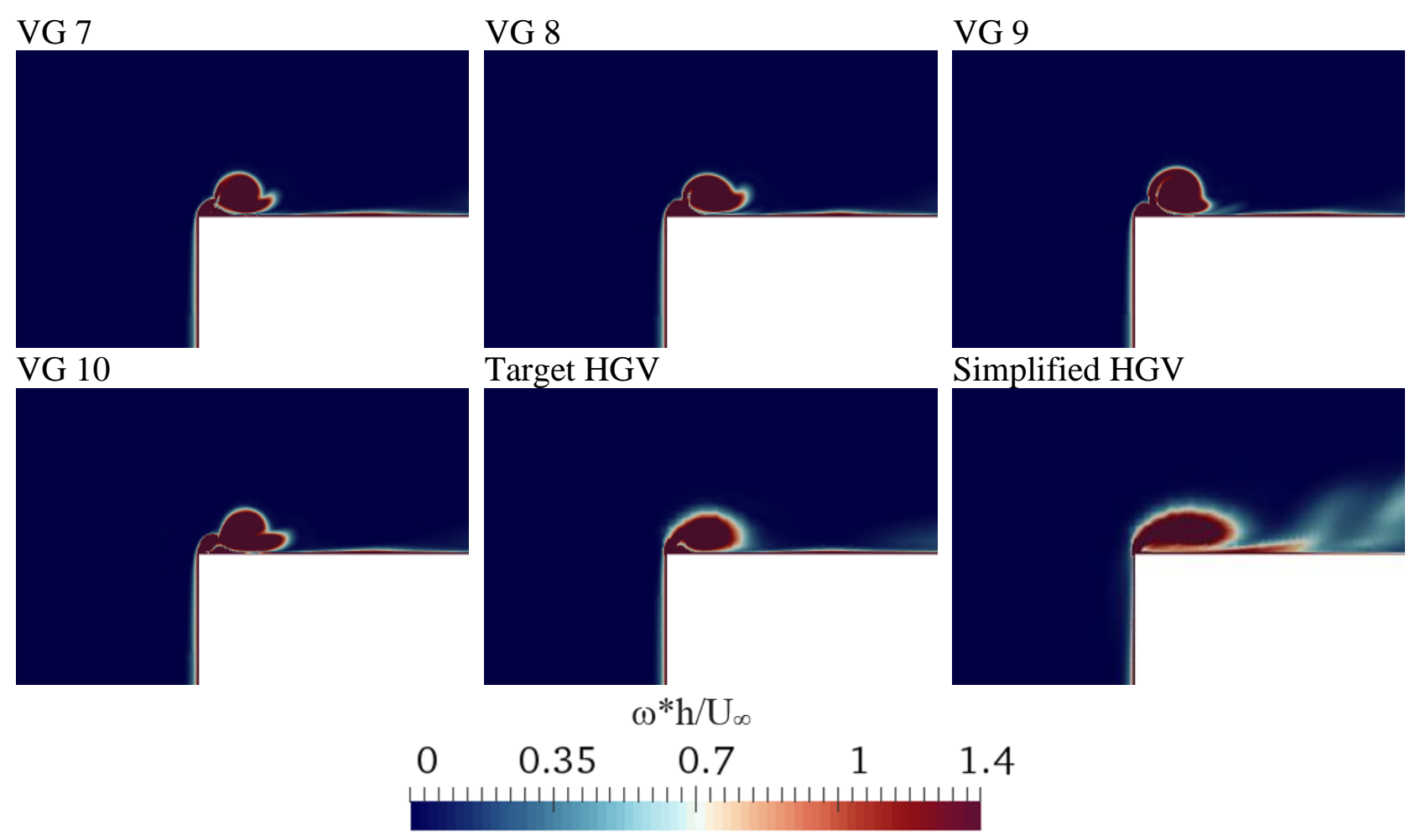

Figure 3-3. Magnitude vorticity on plane C0 for the tested VGS.

\subsection{Front-trailer devices installed along the sides/top of the trailer}

Steady state analysis

As reported in section 2.5, the simplest way to reduce the side force acting on the HGV is to change the shape of the trailer from the standard rectangular one, making the corner between the top and the side of the trailer as smooth as possible. In section 2.5, the smoother transition between the side and the top of the trailer was obtained reducing the load capacity of the trailer. The same results were obtained mounting external devices on the side/top of the trailer. The performances of the Fronttrailer devices with device length $\mathrm{a}=0.45 \mathrm{~m}$ were tested in this cross-wind condition and compared to the target vehicle. The device reduced the overturning moment by about $1.5 \%$ (see Table 3-5). When installing the side devices, with the same shape of the front-trailer one (device " $\mathrm{H}$ "), a positive overturning reduction was observed by $7.4 \%$. When both device " $\mathrm{H}$ " and device "I" were mounted on the trailer, the overturning reduction was around $9 \%$.

As pointed out in previous author's work [23], the configuration devices " $D+E$ " and " $F+G$ " seem to be promising strategies for reducing drag, especially in Countries where increasing the maximum vehicle height or width can be problematic. In particular, current regulations already allow aerodynamic devices to exceed the maximum permitted width no more than $5 \mathrm{~cm}$ per size of the trailer. Therefore, the combination of devices " $\mathrm{D}$ ", "E" and " $\mathrm{H}$ " was tested. The results show a mitigation of the overturning moment by about $7.5 \%$ while the drag reduction in front wind is about $4 \%$ [23]. In the isovorticity at plane $\mathrm{C} 0$ and $\mathrm{C} 1$, as shown in section 2.5, it can be observed that there were some significant changes in the vortex shape. Nevertheless, they were much lower than the one obtained for the rounded corner shape with $\mathrm{R}=0.3 \mathrm{~m}$ (see Figure 3-1, Figure 3-2, Figure 3-5, Figure 3-6). In Figure 3-5 and Figure 3-6, there are no main differences between the vorticity in the target vehicle and in the one with the " $\mathrm{D}+\mathrm{E}+\mathrm{F}+\mathrm{G}$ " devices (the Front-rear trailer device) installed on it. In fact, this device is developed only to reduce drag. 


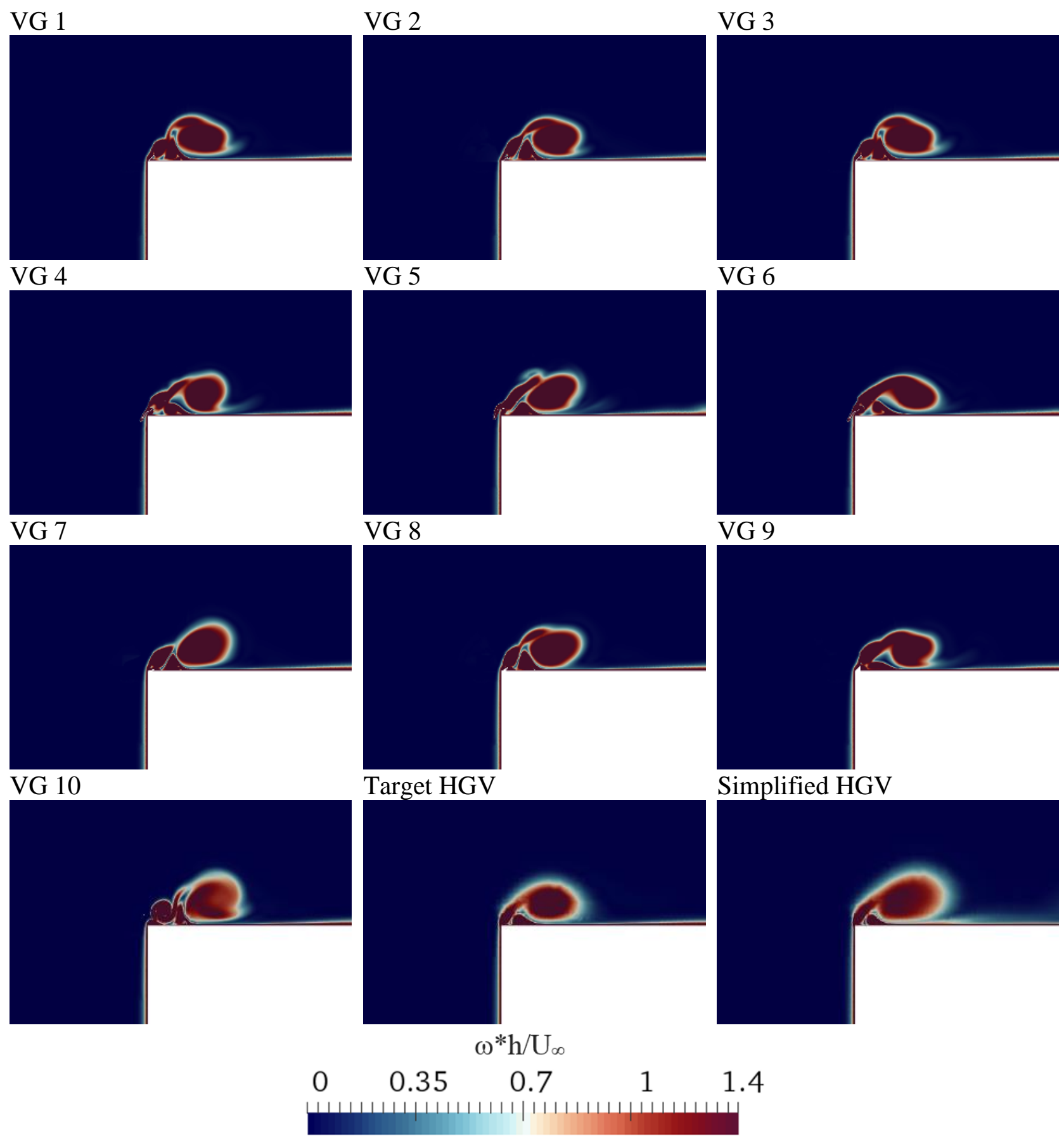

Figure 3-4. Magnitude vorticity on plane C1 for the tested VGS.

Table 3-5. Force coefficient reduction for the tested devices compared to the target vehicle.

\begin{tabular}{|l|c|c|c|}
\hline \multicolumn{1}{|c|}{ Device } & Cmx total & Cy_tot & Cz_tot \\
\hline & $\%$ & $\%$ & $\%$ \\
\hline $\mathrm{D}+\mathrm{E}+\mathrm{F}+\mathrm{G}$ & 1.50 & 2.40 & 1.12 \\
\hline $\mathrm{D}+\mathrm{E}+\mathrm{F}+\mathrm{G}+\mathrm{H}$ & 7.41 & 9.84 & -6.18 \\
\hline $\mathrm{D}+\mathrm{E}+\mathrm{F}+\mathrm{G}+\mathrm{I}$ & 3.37 & 2.87 & 2.14 \\
\hline $\mathrm{D}+\mathrm{E}+\mathrm{F}+\mathrm{G}+\mathrm{H}+\mathrm{I}$ & 9.18 & 10.67 & -6.91 \\
\hline $\mathrm{D}+\mathrm{E}+\mathrm{H}$ & 7.52 & 9.53 & -5.73 \\
\hline
\end{tabular}


When both the side devices and the top one were installed on the trailer, coupled with the front trailer device (device " $\mathrm{D}+\mathrm{E}+\mathrm{F}+\mathrm{G}+\mathrm{H}+\mathrm{I}$ "), a significant vortex reduction was obtained on the $\mathrm{C} 0$ and $\mathrm{C} 1$ planes, and the overturning moment was accordingly reduced by about $9.20 \%$. The vortices generated by the device " $\mathrm{D}+\mathrm{E}+\mathrm{F}+\mathrm{G}+\mathrm{H}$ " and " $\mathrm{D}+\mathrm{E}+\mathrm{F}+\mathrm{G}+\mathrm{I}$ " were in between the aforementioned two configurations (device " $\mathrm{D}+\mathrm{E}+\mathrm{F}+\mathrm{G}$ " and device " $\mathrm{D}+\mathrm{E}+\mathrm{F}+\mathrm{G}+\mathrm{H}+\mathrm{I}$ "), even though a higher vortex reduction can be seen in the " $\mathrm{D}+\mathrm{E}+\mathrm{F}+\mathrm{G}+\mathrm{H}$ " configuration. The device installed on the side of the trailer forced the flow to bend over the device shape more, with a delayed separation due to the rounded shape instead of the sharp corner. On the contrary, on the " $\mathrm{D}+\mathrm{E}+\mathrm{F}+\mathrm{G}+\mathrm{I}$ " device the separation started as on the " $\mathrm{D}+\mathrm{E}+\mathrm{F}+\mathrm{G}$ " device, and then the flow is not able to be attached to the device. As a result, a higher vorticity is observed close to the device, lowering the pressure close to the windward edge, resulting in a lower reduction of overturning moment. When only the lateral devices were installed, configuration " $\mathrm{D}+\mathrm{E}+\mathrm{H}$ ", no significant differences from the " $\mathrm{D}+\mathrm{E}+\mathrm{F}+\mathrm{G}+\mathrm{H}$ " configuration were observed, suggesting that this configuration could be the most suitable one for users to adopt and for legislators to accept.

Time variant analysis

As illustrated, several strategies can be used to successfully reduce the vehicle overturning moment in cross-wind. The most promising seems to be the change of the trailer shape to a rounded corner. Although the rounded corner ensures a higher performance and requires a very low reduction of load volume, the author believes that this strategy will be very hard for users and manufacturers to accept. On the contrary, the strategy of "adding" external passive devices on the existing trailer shape seems to be the easiest solution to be adopted by the "truck community" (as shown in the past for other devices, as for cab roof fairings); in particular, if said device does not exceed the maximum vehicle dimension permitted by the current regulations. Hence, it was decided to perform a time variant analysis only on the device " $\mathrm{D}+\mathrm{E}+\mathrm{H}$ ".

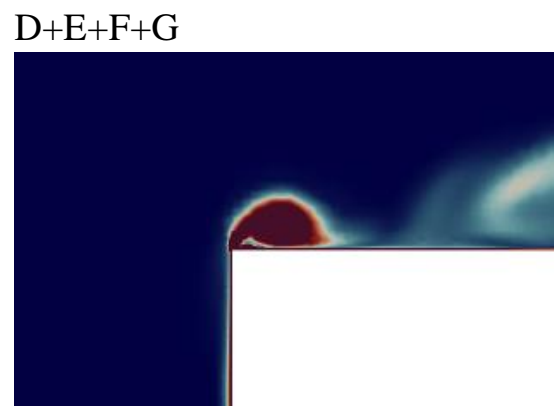

$\mathrm{D}+\mathrm{E}+\mathrm{F}+\mathrm{G}+\mathrm{H}+\mathrm{I}$

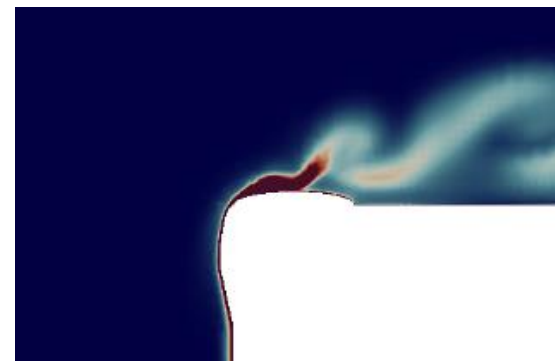

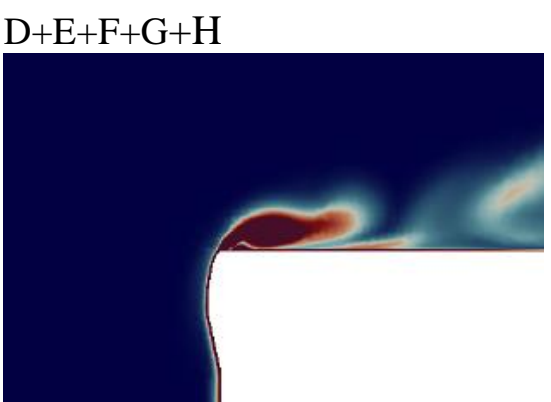

$\mathrm{D}+\mathrm{E}+\mathrm{H}$

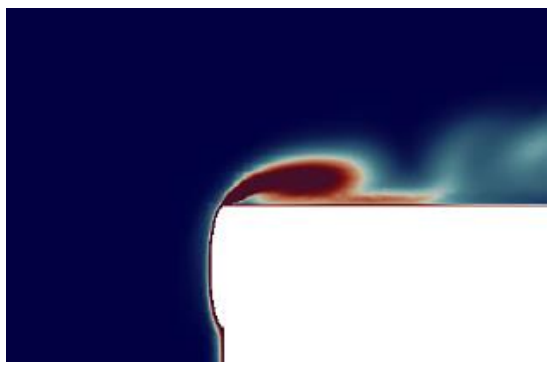

$\omega * \mathrm{~h} / \mathrm{U}_{\infty}$

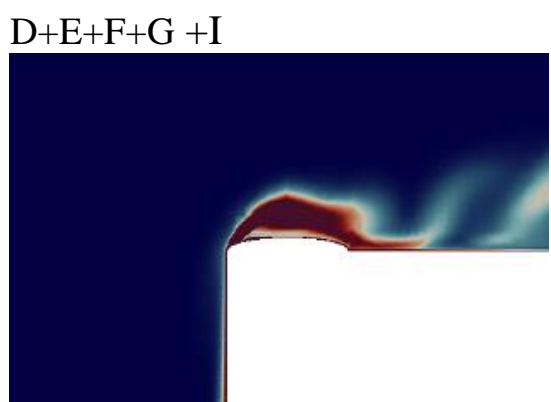

Target HGV

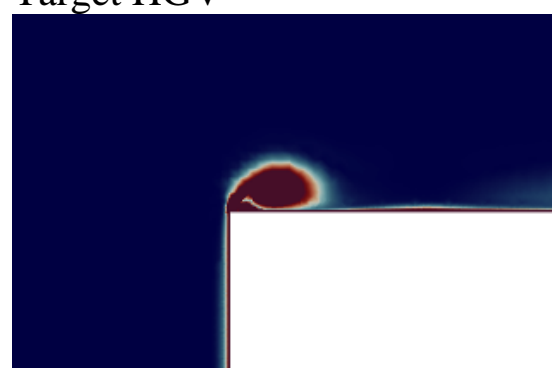

1.4

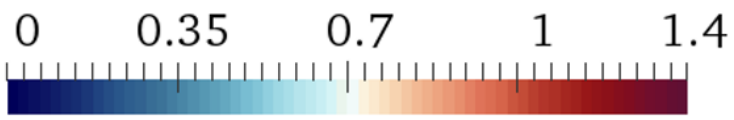

Figure 3-5. Magnitude vorticity on plane $\mathrm{C} 0$ for the tested devices. 
Table 3-6, reports the average reduction of the lift, side force and overturning moment compared to the target vehicle for the device tested. Compared to the steady state simulation, the main differences were observed in the lift prediction. In fact, there seems to be a lift reduction around $1.7 \%$, while in the steady state simulation the lift increased by about $5.7 \%$ (see Table 3-6). The overturning moment was reduced by about $8 \%$.

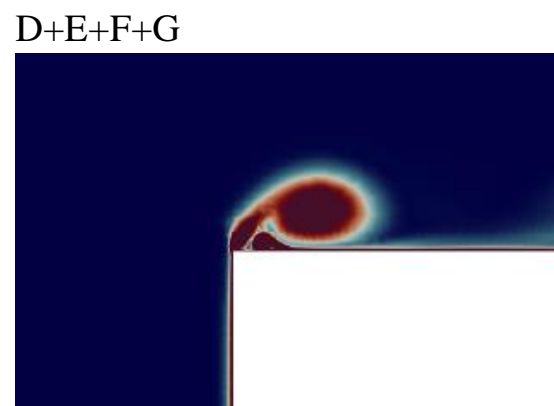

$\mathrm{D}+\mathrm{E}+\mathrm{F}+\mathrm{G}+\mathrm{H}+\mathrm{I}$

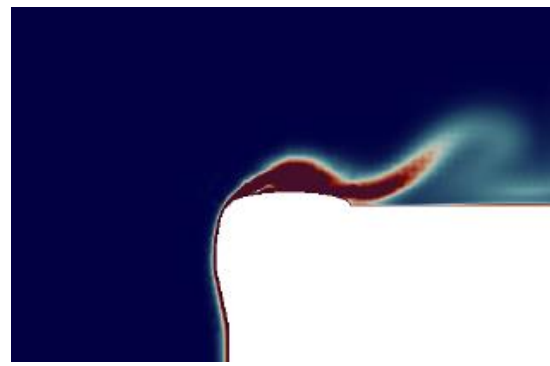

\section{0}

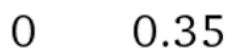

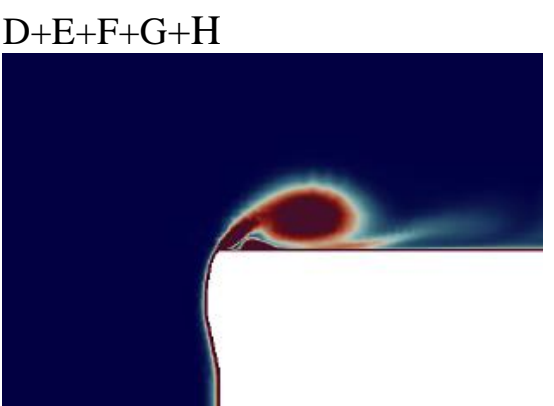

$\mathrm{D}+\mathrm{E}+\mathrm{H}$

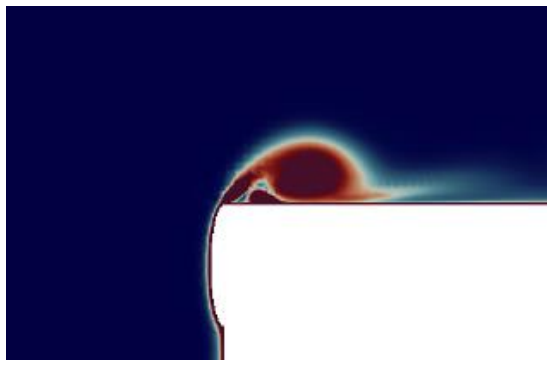

$\omega^{*} \mathrm{~h} / \mathrm{U}_{\infty}$

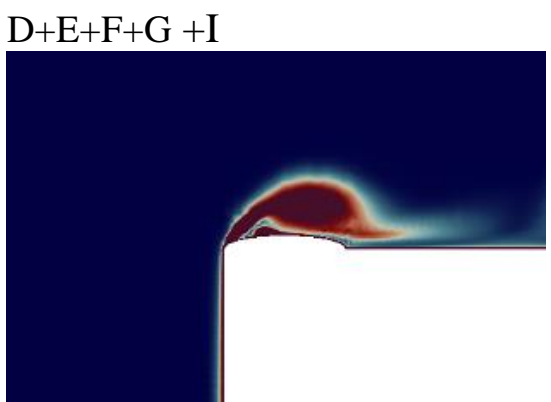

Target $\mathrm{HGV}$

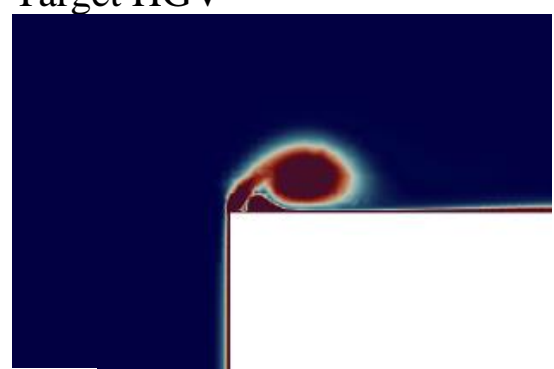

Figure 3-6. Magnitude vorticity on plane $\mathrm{C} 1$ for the tested devices.

Table 3-6. Force coefficient reduction for the tested devices compared to the target vehicle.

\begin{tabular}{|c|c|c|c|}
\hline Device & Cmx total & Cy_tot & Cz_tot \\
\hline & $\%$ & $\%$ & $\%$ \\
\hline D+E+H (RANS) & 7.52 & 9.53 & -5.73 \\
\hline D+E+H (DES) & $8.28 \%$ & $5.82 \%$ & $1.67 \%$ \\
\hline
\end{tabular}

Figure 3-7 and Figure 3-8 show the instantaneous iso-vorticity at planes C0 and C1 after $3 s$ of simulation. The time step is selected to be representative of the differences in the separation on the top of the trailer between the target vehicle and the one equipped with the device. We can observe that there were no significant changes in the first separation over the top of the trailer between the steady state simulation and the time variant one, as highlighted in section 3.4. Of course, a more accurate turbulence model predicts a much more turbulent structure downwind than the steady state simulation, as marked in the next figures.

The DES simulation predicts more vortices structure downwind than the RANS time invariant simulation [34], [35]. This differences between the used turbulence model, were responsible for the change of the side and lift force computed over the vehicle surface.

Nevertheless, it is also possible to appreciate the change in the flow structure in the first separation on the leading edge of the trailer between the target vehicle and the one with the devices installed on it. 
Target vehicle

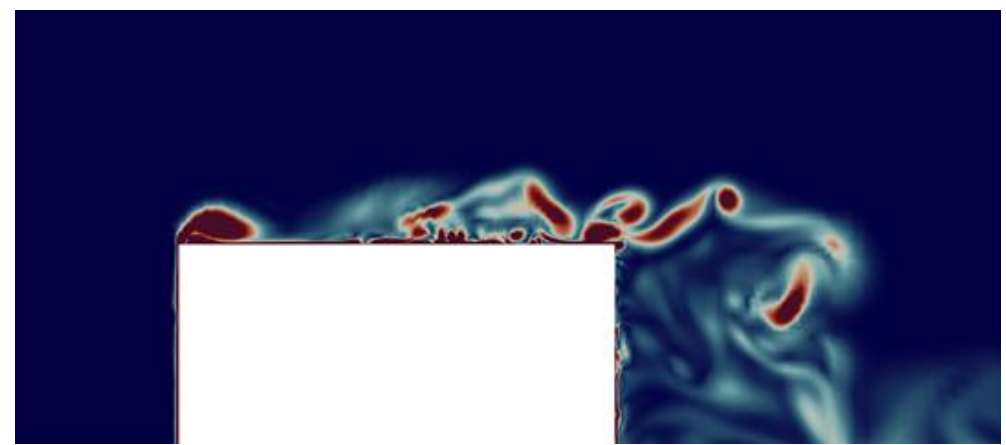

Truck with the device " $\mathrm{D}+\mathrm{E}+\mathrm{H}$ " installed

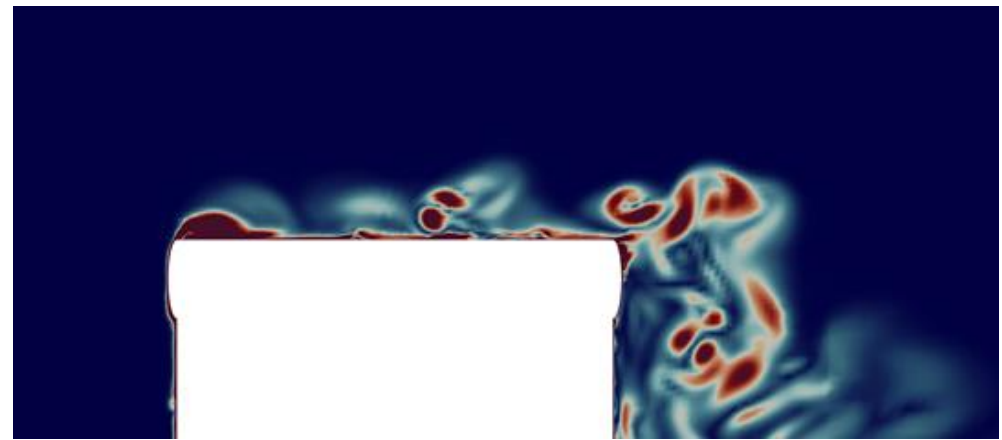

Figure 3-7. Comparison between instantaneous magnitude vorticity on plane $\mathrm{C} 0$ for the target vehicle and the vehicle equipped with the device " $\mathrm{D}+\mathrm{E}+\mathrm{H}$ ".

Target vehicle

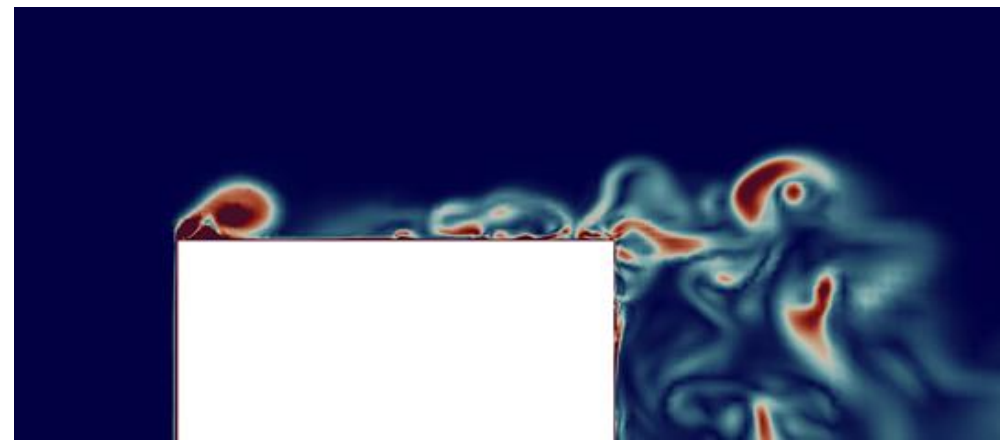

Truck with the device " $\mathrm{D}+\mathrm{E}+\mathrm{H}$ " installed

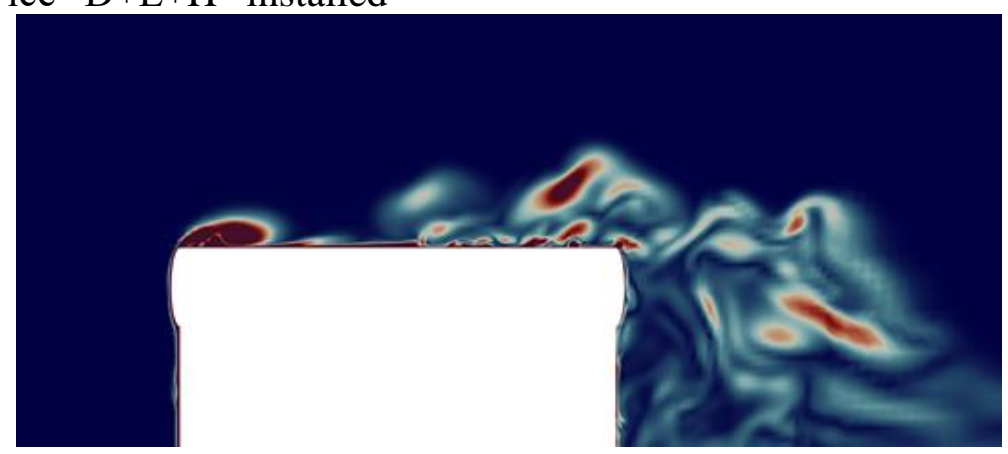

Figure 3-8. Comparison between instantaneous magnitude vorticity on plane $\mathrm{C} 1$ for the target vehicle and the vehicle equipped with the device " $\mathrm{D}+\mathrm{E}+\mathrm{H}$. 


\section{Conclusion}

As illustrated, several strategies can be used to successfully reduce the vehicle overturning moment in cross-wind.

The first way tested to mitigate the overturning risk was the change of the shape of the trailer.

All the shapes of the trailer tested significantly reduced the vehicle overturning moment. Increasing the length of the $\mathrm{R}$ parameter, the reduction of the overturning moment increased in all of the shapes tested.

When using the reduction of the load capacity as parameter to compare the different kinds of trailer shapes, for a load capacity reduction of $0.60 \%$, it is possible to reduce the overturning moment by $25 \%$ with a rounded corner, $18 \%$ with an inclined one, while for the corner cut it is around $10-13 \%$. At a constant volume reduction, the rounded corner is the one that shows the highest performance with a limited reduction of load capacity below $1 \%$.

VGs were positioned on the top separation leading-edge, as shown in red, in Figure 2-14, to reduce the overturning moment.

Comparing the performance of the VGs with the one obtained in the previous strategy, the VGs do not seem a promising solution to mitigate the overturning risk, reducing the overturning moment no more than $2.4 \%$.

The strategy of "adding" external passive devices on the existing trailer was adopted. Several lateral and top devices were added onto the trailer. Their shapes were based on the Front-rear trailer device previously designed and patented by the author. This strategy seems to be the easiest to be adopted by the "truck community" (as shown in the past for other devices, such as cab roof fairings); in particular, if said device does not exceed the maximum vehicle dimension permitted by current regulations, as the case of the device " $\mathrm{D}+\mathrm{E}+\mathrm{H}$ ". The proposed device " $\mathrm{D}+\mathrm{E}+\mathrm{H}$ " can reduce the whole overturning moment by about $7.5 \%-8 \%$, both in steady-state simulations and time variant ones.

\section{Acknowledge}

I thank the CINECA award, under the ISCRA initiatives, for the availability of high performance computing resources and support. 


\section{References}

[1] Baker, C.J., "A simplified analysis of various types of wind-induced road vehicle accidents," Journal of Wind Engineering and Industrial Aerodynamics, 22(1), 69-85, 1986.

[2] Baker, C.J., "Measures to control vehicle movement at exposed sites during windy periods," Journal of Wind Engineering and Industrial Aerodynamics, 25(2), 151-161, 1987.

[3] Baker, C.J., Cheli, F., Orellano, A., Paradot, N., Proppe, C., Rocchi, D., "Cross-wind effects on road and rail vehicles," Vehicle System Dynamics, 47(8), 983-1022, 2009.

[4] Baker, C.J., Reynolds, S., "Wind-induced accidents of road vehicles," Accident Analysis \& Prevention, 24(6), 559-575, 1992.

[5] Cheli, F., Corradi, R., Sabbioni, E., Tomasini, G., "Wind tunnel tests on heavy road vehicles: Cross-wind induced loads - Part 1," Journal of Wind Engineering and Industrial Aerodynamics, 99, 1000-1010, 2011.

[6] Cheli, F., Corradi, R., Sabbioni, E., Tomasini, G., "Wind tunnel tests on heavy road vehicles: Cross-wind induced loads - Part 2," Journal of Wind Engineering and Industrial Aerodynamics, 99, 1011-1024, 2011.

[7] Cheli F., Diana G., Rocchi D., Testa M., Tomasini G., Schito P.," A new stochastic approach for the regulation of the train velocity in presence of cross wind: an application on the Rome-Naples high-speed line", CWE2010, Chapel Hill (NC) USA, May 2010

[8] Cheli, F., Belforte, P., Melzi, S., Sabbioni, E. and Tomasini, G., "Numerical-experimental approach for evaluating cross-wind aerodynamic effects on heavy vehicles," Vehicle System Dynamics, 44(1), 791-804, 2006, doi: 10.1080/00423110600886689.

[9] Salati, L., Cheli, F., and Schito, P., "Heavy Truck Drag Reduction Obtained from Devices Installed on the Trailer," SAE Int. J. Commer. Veh. 8(2):747-760, 2015, doi:10.4271/2015-012898.

[10] Salati, L., Schito, P., Rocchi, D., Sabbioni, E., “Aerodynamic Study on a Heavy Truck Passing by a Bridge Pylon under Crosswinds Using CFD”, Journal of Bridge Engineering. Volume 23 Issue 9, September 2018, DOI: 10.1061/(ASCE)BE.1943-5592.0001277.

[11] McArthur, D., Burton, D., Thompson, M., Sheridan, J., "An experimental characterisation of the wake of a detailed heavy vehicle in cross-wind," Journal of wind engineering and industrial aerodynamics, Volume 175, April 2018, Pages 364-375, https://doi.org/10.1016/j.jweia.2018.01.033.

[12] Charuvisit, S., Kimurab K., Fujinoc Y. "Experimental and semi-analytical studies on the aerodynamic forces acting on a vehicle passing through the wake of a bridge tower in cross wind," Journal of Wind Engineering and Industrial Aerodynamics Volume 92 Issue 9 (2004) 749-780. doi:10.1016/j.jweia.2004.04.001.

[13] Argentini T., Ozkan E., Rocchi D., Rosa L., Zasso A., "Cross-wind effects on a vehicle crossing the wake of a bridge pylon," Journal of wind engineering and industrial aerodynamics, 2011, pp. 734-740.

[14] Rossitto, G., Sicot, C., Ferrand, "Influence of afterbody rounding on the pressure distribution over a fastback vehicle," Experiments in Fluids, 57 (3). 1-12. ISSN 0723-4864 Exp Fluids (2016) 57: 43. https://doi.org/10.1007/s00348-016-2120-1.

[15] Drollinger, R., "Heavy Duty Truck Aerodynamics," SAE Technical Paper 870001, 1987, doi:10.4271/870001.

[16] Cooper, K., "Truck Aerodynamics Reborn - Lessons from the Past," SAE Technical Paper 2003-01-3376, 2003, doi:10.4271/2003-01-3376.

[17] Leuschen, J., Cooper, K.R., "Summary of full-scale wind tunnel tests of aerodynamics dragreducing devices for tractor-trailers. The Aerodynamics of Heavy Vehicles II: Trucks, Buses, and Trains,” Springer, New York, 2009, pp. 451-462, doi:10.1007/978-3-540-85070-0_41. 
[18] Garry, K.P., "Development of container-mounted devices for reducing the aerodynamics drag of commercial vehicles," Journal of Wind Engineering and Industrial Aerodynamics 9, 113-124, 1981, doi:10.1016/0167-6105(81)90082-9.

[19] Watkins, S., Saunders, J.W., Hoffman, P.H., "Comparison of road and wind-tunnel drag reductions for commercial vehicles," Journal of Wind Engineering and Industrial Aerodynamics 49, 1993, pp. 411-420.

[20] Garry, K.P., "A review of commercial vehicle aerodynamics drag reduction techniques," Proceedings of the Institution of Mechanical Engineers D: Transport Engineering 199, 215-220, 1985, doi: 10.1243/PIME_PROC_1985_199_159_01.

[21] Ingram K., "The wind-averaged drag coefficient applied to heavy goods vehicles," Transport and Road Research Laboratory, TRRL Supplementary Report 392, 1978.

[22] McCallen, R., Salari, Ortega, J., Castellucci, P., Browand, F., Hammache, M. et al., "DOE's effort to reduce truck aerodynamics drag - joint experiments and computations lead to smart design," presented at the 34th AIAA Fluid Dynamics Conference and Exhibit, AIAA 2004-2249, Portland, June 22, 2004, UCRL-CONF-204819.

[23] Salati, L., Cheli, F., and Schito, P., "Wind tunnel experiment on a heavy truck equipped with Front-rear trailer device." Journal of Wind Engineering and Industrial Aerodynamic. 10.1016/j.jweia.2017.09.016.

[24] Taylor, H., "The Elimination of Diffuser Separation by Vortex Generators," United Aircraft Corporation Rept. R-4012-3, June 1947.

[25] Gillen, T., Rybalko, M., and Loth, E., "Vortex Generators for Diffuser of Axisymmetric Supersonic Inlets," 5th Flow Control Conference, AIAA Paper 2010-4253, July 2010, pp. 1-18.

[26] Gyatt, G., "Development and Testing of Vortex Generators for Small Horizontal Axis Wind Turbines," Final Report AeroVironment, Inc., Monrovia, CA, July 1986.

[27] Timmer, W. A., and van Rooij, R. P. J. O. M., "Roughness Sensitivity Considerations for Thick Rotor Blade Airfoils," AIAA Paper 2003-0350, 2003, pp. 1-10.

[28] Tai, T. C., "Effect of Midwing Vortex Generators on V-22 Aircraft Forward-Flight Aerodynamics," Journal of Aircraft, Vol. 40, No. 4, 2003, pp. 623-630. doi:10.2514/2.3165.

[29] Lin, J. C., "Review of Research on Low-Profile Vortex Generators to Control Boundary-Layer Separation," Progress in Aerospace Sciences, Vol. 38, Nos. 4-5, 2002, pp. 389-420. doi:10.1016/S0376-0421(02)00010-6.

[30] F. (KTH) Stillfried, S. Wallin, and A. Johansson. An improved passive vortex generator model for ow separation contrSAEol. 5th Flow Control Conference, (July), 2010.

[31] Wood, R. M. \& Bauer, S. X. S. - Simple and Low-Cost Aerodynamic Drag Reduction Devices for Tractor-Trailer Trucks. SAE 2003-01-3377, SAE Truck and Bus Conference and Exposition, Houston, TX, USA, Nov. 2003.

[32] Mugnani. C. "Aerodynamic drag reduction of a tractor trailer using vortex generators: a computational fluid dynamic study". Thesis (M.S., Mechanical Engineering). California State University, Sacramento, 2015.

[33] SAE International Surface Vehicle Recommended Practice, "Guidelines for Aerodynamic Assessment of Medium and Heavy Commercial Ground Vehicles Using Computational Fluid Dynamics," SAE Standard J2966, Rev. Sept. 2013.

[34] OpenFOAM Version 16.12+, http:www.openfoam.org, accessed 2017.

[35] Versteeg, H. K., Malalasekera W., "An Introduction to Computational Fluid Dynamics: The Finite Volume Method," 2nd edition, 2007, Pearson Education (Ed.), ISBN: 9780131274983.

[36] Rocchi, D., Rosa, L., Sabbioni, E., Sbrosi, M., Belloli M," "A numerical-experimental methodology for simulating the aerodynamic forces acting on a moving vehicle passing through the wake of a bridge tower under cross wind," Journal of Wind Engineering and Industrial Aerodynamics, Volumes 106, Pages 256-265, 2012 ISSN 0167-6105, doi.org/10.1016/j.jweia.2012.03.012. 
[37] Stapleford, W., R. and Carr, G., W., "Aerodynamic characteristics of exposed rotating wheels," in MIRA Rep. No. 1970/2, MIRA, 1969.

[38] Salati, L., Schito, P., Cheli, F., "Aerodynamic device for reducing the drag of terrestrial vehicles”. European Patent Office. Patent no. 15810769.8 - 1755. 